Working Paper 04-40

Economics Series 15

July 2004
Departamento de Economía Universidad Carlos III de Madrid

Calle Madrid, 126

28903 Getafe (Spain)

Fax (34) 916249875

\title{
ON THE DEFINITION OF AFFORDABLE PRICES UNDER UNIVERSAL SERVICE OBLIGATIONS
}

\author{
Ramiro Losada ${ }^{1}$
}

\begin{abstract}
In this paper, we investigate the social welfare implications of the European and American definition of affordable prices when a country is divided into independent zones. We find that the European definition is always social welfare superior, because it forces to keep lower prices. We also introduce to new defintions of affordable prices. The first definition advocates for a common price for the unprofitable area. We prove that this definition is social welfare superior to the current definitions. In the second definition denote as "yardstick pricing", we define the affordable prices for the unprofitable areas as a function that does not depende on their own zone profitable area price. We show that yardstick price is more efficient for social welfare when the differences in demand among zones are not very large.
\end{abstract}

\footnotetext{
* I gratefully acknowledge the research supervision of M. Angeles de Frutos and Pedro L. Marín. I also thank the Spanish Ministry of Education and Culture for financial support, grant AP2000-0847. The usual disclaimer applies.
}

\footnotetext{
${ }^{1}$ Department of Economics, Universidad Carlos III de Madrid, Calle Madrid 126, 28903, Getafe, Spain, Tlf: +34 91 6249367, Fax: +34916249875, Email: losada @eco.uc3m.es.
} 


\section{Introduction}

In the telecommunications market regulators place a high value to the access of all consumers to the service. This goal has been termed Universal Service. There are several reasons why regulators may want to pursue the goal of universal service, such as equity, economic development, and even economic efficiency (due to sizeable network externalities). One of the important characteristic of the telecommunications markets is that some countries, e.g. USA or Argentina, have divided their national territory in independent zones, where each zone is a market on its own. ${ }^{1}$

Universal Service has been defined by European and American authorities in a similar way. The European Parliament and the Council stipulate the obligation for the member states that Universal Service is a set of services "made available with the quality specified to all end-users in their territory, irrespective of their geographical location, and, in the light of specific national conditions, at an affordable price". ${ }^{2}$ The American regulator concept of Universal Service consists in "ensuring quality telecommunications services at affordable rates to consumers, in all regions of the nation, including rural, insular, and high-cost areas". 3 Thus one of the most important Universal Service goals is that all consumers must enjoy affordable prices. ${ }^{4}$

Although both regulations seek to set affordable prices, what the different regulators understand for affordable prices is not exactly the same. If we take the American definition of affordable prices, we find: "the Commission shall adopt rules to require that the rates charged by providers of interexchange telecommunication services to subscribers in rural and high cost markets shall not be higher than the rates charged by each such provider to its suscriber in urban markets. Such rules shall also require that a provider of interstate interchange telecommunications services shall provide such services to its subscribers in each state at rates no higher than the rates charged to its subscribers in any other state". ${ }^{5}$ Applying this definition, we find that,

\footnotetext{
${ }^{1}$ There is a tendency to split up the national telecommunication markets, for example in Australia, the government has recently announced that it will introduce competition into USO provision by inviting carriers to tender for the USO in two regional pilot areas.

${ }^{2}$ For further details, see the Directive 2002/22/CE of the European Parliament and the Council.

${ }^{3}$ For further details, see Federal Communications Commission (1996), Docket n 96-45.

${ }^{4}$ This requirement of the Universal Service arises because the price differentials expected to prevail in an unregulated setting are deemed unacceptable by regulators.

${ }^{5}$ For further details, see Telecommunications act (1996)
} 
within USA, there may be different prices.

On the other hand, if we check the European definition of affordable prices, we find: "Affordable price means a price defined by Member States at National level in the light of specific national conditions, and may involve setting common tariffs irrespective of location or special tariff options to deal with the needs of low-income users. Affordability for individual consumers is related to their ability to monitor and control their expenditure". ${ }^{6}$ Thus, the European Union opts for setting a unique price per country, what in principle is more restrictive. Although within EU there can be countries with the national market divided in independent zones where firms do not operate simultaneously in all zones, all firms are obliged to set the same price. We have that there are two streams about how to set affordable prices, one more restrictive, the European, and the other, the American, more concerned with the "no intervention" paradigm.

In order to attain the objectives of Universal Service, the regulator must impose Universal Service Obligations (USOs hereafter) on the industry. ${ }^{7}$ In the case of affordable prices, USOs are constraints imposed by regulators on firms. These constraints take the form of either uniform pricing, which forces the firms to offer their services to all its consumers at a geographically uniform price, or a price cap, which establishes a maximum average price of firms' services. Telecommunications markets are generally characterized by a small number of networks, so that the resulting competition will be oligopolistic. This makes that constraints imposed by USOs may create strategic effects, and therefore affect competition.

The academic literature has not treated very deeply the definition of affordable prices. Few papers, Valletti et al. (2002) or Iozzi (2001), study the impact of the price constraints on competition. They compare the scenario where there is a unique zone which consists in two markets (profitable and unprofitable) with no price restrictions with a scenario where firms are forced to set a uniform price in both markets. In these papers, as in others such as Chone et al. (2002), Anton et al. (2002), Gasmi et al. (2000) or Rosston and Wimmer (2000), the key point is that they consider only an unprofitable market and a profitable market. In this context, they always consider

\footnotetext{
${ }^{6}$ For further details, see Directive 2002/22/CE of the European Parliament and Council (2002).

${ }^{7}$ In the countries where the Telecommunication market was recently open to competition, for example Spain, USOs are only applied to the Incumbent Carrier, Telefonica in the case of Spain.
} 
that an affordable price for the unprofitable market is equal to the price of the profitable market. ${ }^{8}$ With this common setup, the literature concludes that setting a common price in both, the unprofitable and profitable market, creates an strategic link between both markets that makes higher the equilibrium price. This is so, because one of the firms is a monopolist in the unprofitable market. This firm is always interesting in relaxing competition in the profitable market to enjoy a higher profit in the unprofitable market through a price increase.

In this paper, we address the question of which of the regulatory definitions of affordable prices at work is better from a social point of view. This needs of models which are closer to reality. We need to extend the existing models of USOs by considering a country which is divided in zones where each zone consists in an unprofitable area and a profitable area. ${ }^{9}$ We also propose two new definitions of affordable prices. In one of these definitions, the price in all unprofitable areas in the country is a convex combination of the prices in the profitable areas. In the other definition, we propose that the price in any unprofitable area is a function, e.g. the sample mean, of the prices of all profitable areas but the profitable area the unprofitable area is attached to. We denote this definition of affordable prices "yardstick pricing".

To do so, we extend the model by Anton et al. (2002). We need to consider that the country is divided in more than one independent zone, each one with one profitable area and one unprofitable area. ${ }^{10}$ We show that the European regulation is social welfare superior to the American regulation. ${ }^{11}$ This is because the European regulation applies to the whole country the minimum price between the different prices that the American regulation sets in the different zones of the country.

We also show that our first definition of affordable prices is welfare superior to the European. Setting the same price in all the unprofitable areas as a convex combination of the prices in the profitable areas allows us to break

\footnotetext{
${ }^{8}$ In some of these papers, it is defined the price of the unprofitable area as lower or equal than the price in the profitable area. In equilibrium, both prices are always equal.

${ }^{9}$ All the unprofitable areas form the profitable market. All the profitable areas form the profitable market.

${ }^{10}$ We represent our set-up with a graph in Figure 1. Area 1 of the U market and area 1 of the $\mathrm{R}$ market form zone 1 . Area 2 of the $\mathrm{U}$ market and area 2 of the $\mathrm{R}$ market form zone 2. This is the present situation in Argentina and USA, where the countries are divided in more than one independent zone.

${ }^{11}$ Under the assumption taken by the literature of only one zone (which consists in the whole unprofitable area and the whole profitable area), both regulations are identical.
} 
partially the strategic link between the profitable and unprofitable areas. We can enjoy scenarios where the social welfare is at least equal to the situation where the country enjoys the price from the European regulation for some of the areas but for one profitable area which enjoys an even lower price.

To conclude we show that with our second definition, yardstick pricing, we can break completely the strategic link between the profitable and unprofitable areas. This leads to a much lower price than under current regulatory regimes definitions and the first proposed definition. But there is a limit to this definition. We need consumers' demands in the different zones to be very similar. Otherwise, it may yield undesirable social welfare results.

This paper is organized as follows. Section 2 describes the model. Section 3 analyzes the current regulatory frameworks and their implications for Social Welfare. In Section 4, the first new definition of affordable prices is presented and analyzed. In section 5, we present and analyze yardstick pricing. Section 6 concludes.

\section{The model}

\subsection{Costs and Demands}

A country has two differentiated markets, one urban (U) and one rural (R). Demand in the $\mathrm{U}$ market is $D^{U}(p)=1-p$, and in the $\mathrm{R}$ market is $D^{R}(p)=$ $b(1-p)$, where $p$ is the market price and $b>0$. Both market demands have a common price intercept at $p=1$, whereas the slope coefficient $b$ allows the $\mathrm{R}$ market demand to be smaller or larger than the $\mathrm{U}$ market demand. In many situations, we expect the $\mathrm{R}$ market demand to be smaller. ${ }^{12}$

Each market is divided into two areas that can be of equal or different size. We denote by $D_{1}^{U}(p)=\alpha_{1}(1-p)$ and $D_{2}^{U}(p)=\alpha_{2}(1-p), \alpha_{1}+\alpha_{2}=1$, the demands of areas 1 and 2 of the $\mathrm{U}$ market. The demands of areas 1 and 2 of the R market are, respectively, $D_{1}^{R}(p)=\beta_{1} b(1-p)$ and $D_{2}^{R}(p)=\beta_{2} b(1-p)$, with $\beta_{1}+\beta_{2}=1$. Each area of the $\mathrm{R}$ market is attached to one of the areas of the $\mathrm{U}$ market, to constitute a zone. More precisely, area 1 of the $\mathrm{R}$ market is attached to area 1 of the $\mathrm{U}$ market, and area 2 of the $\mathrm{R}$ market is attached

\footnotetext{
${ }^{12}$ This modelling strategy for the demand functions is taken from Anton et al (2002). Note that they describe a country where the differences between consumers in the two markets are not large.
} 
to area 2 of the $\mathrm{U}$ market. ${ }^{13}$ They constitute zone 1 and zone 2 respectively. To further clarify the country division, see figure 1 .

The fixed cost of area 1 and 2 of the $U$ market are respectively $F_{1}^{U}$ and $F_{2}^{U}$. The fixed costs of area 1 and 2 of the $\mathrm{R}$ market are $F_{1}^{R}$ and $F_{2}^{R} \cdot{ }^{14}$ There is a constant marginal cost, $c$, which is the same for the whole country. We assume, without loss of generality, that $c=0 .{ }^{15}$ Finally, there is a duopoly in each zone. To simplify the analysis, we assume that no firm operates in both zones. The firms that serve the areas of the $\mathrm{R}$ market and the subsidies that these firms receive for being in charge of USOs are determined by a political decision, and it is here exogenously given.

\subsection{The game}

We consider a simple complete information game. The timing of the game goes as follows:

1. Firms in both duopolies choose quantities in their areas of the U market. We denote by $q_{i j}$, the quantity that the firm $i=S, N$ produces in the area $j=1,2$, where $S$ denotes the firms which provides the service obligations and hence operates in both areas, and $N$ denotes the firm which only operates in the $\mathrm{U}$ area. The prices in each area of the $\mathrm{U}$ market are:

$$
p_{j}^{U}=1-\frac{\left(q_{S j}+q_{N j}\right)}{\alpha_{j}}, j=1,2
$$

2. The prices in the areas of the $\mathrm{R}$ market are determined through different rules which depend on the definition of affordable prices the government adopts.

3. Each firm payoffs are realized, where firms payoffs are the sum of the profits, including any subsidy.

\footnotetext{
${ }^{13}$ This set-up is consistent, for instance, with the situation in Argentina and the USA. Both countries have been divided into zones, and within zones there are profitable and unprofitable areas.

${ }^{14}$ In general, we may suppose that the size of the fixed costs are not perfectly correlated with the size of the demand that each area has. Under this assumption, we can model all kind of countries, with different density of population and orography.

${ }^{15}$ This assumption is consistent with the fact that variable costs in industries that support USOs are close to zero, as for example in telecommunications or water.
} 
The Cournot competition in the U market serves to streamline the analysis and allow us to consider a homogeneous good for which the cross-area price constraints are unambiguous. ${ }^{16}$ We look for the subgame perfect equilibrium of this game focusing on pure strategies.

\subsection{Social Welfare}

We take two different measueres of social welfare. In the first one, $S W_{1}$, social welfare is the sum of consumers surplus plus firms profits in each zone. This is the standard definition of social welfare when analyzing regulatory problems. In the second one, $S W_{2}$, social welfare is only the sum of consumers' surplus in the $\mathrm{R}$ market. ${ }^{17}$ This is an extreme representation of using USOs as a way to promote a more harmonious distribution away from large metropolitan areas. $^{18}$

\section{Benchmarks: Current definitions of afford- able prices}

We begin our discussion by studying the different definitions of affordable prices and their implications for social welfare.

As we have described in the introduction, we face two different streams on how to set affordable prices when a country has more than one profitable and unprofitable area. We study first the one leaded by the Federal Communication Commission in the USA. This definition advocates for a price cap in each area of the $R$ market in such a way that the price cannot be larger than the price set in the area of the $\mathrm{U}$ market which it is attached to, i.e. $p_{j}^{R} \leq p_{j}^{U}$, for $j=1,2 .{ }^{19}$ In other words, within a zone, consumers in the $\mathrm{R}$ area cannot be charged higher prices than consumers in the $\mathrm{U}$ area. We

\footnotetext{
${ }^{16}$ As an alternative strategic mode, we could employ price setting competition (differentiated Bertrand). While this does not alter the basic strategic link between the $\mathrm{U}$ and $\mathrm{R}$ markets, it does introduce additional issues such as how to interpret the cross-areas price constraints when products are differentiated.

${ }^{17} S W_{2}$ is consistent with a regulator who wants to base distributional comparisons on the well-being of the USOs target group.

${ }^{18}$ Alternatively, it can be argued that $S W_{2}$ represents the objective function of a regulator captured by rural consumers. In a different context than ours, it has been shown that the strong farmer unions may capture a regulator by political lobbying.

${ }^{19}$ For further details, see Telecommunications Act (1996), section 254.
} 
introduce this constraint into our game at the third stage, and we proceed to solve it by backward induction. ${ }^{20}$

First, we look for the price in the areas of the $\mathrm{R}$ market. It is straightforward to see that the constraints $p_{j}^{R} \leq p_{j}^{U}$ are going to be binding in equilibrium. Note that the monopoly prices in the areas of the $\mathrm{R}$ market are higher than the equilibrium prices in the respective areas of the $\mathrm{U}$ market, so that $p_{j}^{R}=p_{j}^{U}$, for both $j=1,2$.

At the second stage, we search for the equilibrium quantities. Recall that we denote by $q_{i j}$ the quantity that firm $i=S, N$, supplies in the $\mathrm{U}$ area of the zone it belongs to. Thus, given the quantities supplied in each area of the $\mathrm{U}$ market, prices in zone $j$ are $p_{j}^{U}=1-\frac{\left(q_{S j}+q_{N j}\right)}{\alpha_{j}}$ for $j=1,2$. Consequently, using $p_{j}^{R}=p_{j}^{U}$, profits for the firms that operate in both areas of a given zone are:

$$
\Pi_{S j}=\left(1-\frac{\left(q_{S j}+q_{N j}\right)}{\alpha_{j}}\right)\left(q_{S j}+\frac{\beta_{j} b\left(q_{S j}+q_{N j}\right)}{\alpha_{j}}\right)-F_{j}^{U}-F_{j}^{R}+s_{j},
$$

where $s_{j}$ stands for the subsidy that a firm providing USOs receives from the government.

Profits for the firms that only operate in the $\mathrm{U}$ areas are:

$$
\Pi_{N j}=\left(1-\frac{\left(q_{S j}+q_{N j}\right)}{\alpha_{j}}\right) q_{N j}-F_{j}^{U} .
$$

Given the profit functions, we derive the reaction functions, which are:

$$
\begin{gathered}
r^{S j}\left(q_{N j}\right)=\frac{\alpha_{j}}{2}-\frac{\left(\alpha_{j}+2 \beta_{j} b\right) q_{N j}}{2\left(\alpha_{j}+\beta_{j} b\right)} \\
r^{N j}\left(q_{S j}\right)=\frac{\alpha_{j}-q_{S j}}{2} .
\end{gathered}
$$

\footnotetext{
${ }^{20}$ Given the resulting model, there are some remarks that should be made. First, the adopted time of events is the one that makes the cross-areas constraints operate in a natural way. If quantities in both markets were set simultaneously, it would create the problem of how to impose the price constraints in the areas of the $\mathrm{R}$ market. Second, the firms that provide USOs should not be viewed as price takers in the areas of the $\mathrm{R}$ market. Given the cross-areas price constraints, the firms are free to set any price in the areas of the $\mathrm{R}$ market up to the ceiling. More importantly, the ceiling is endogenous with respect to the firms actions.
} 
The reaction functions yield the equilibrium quantities:

$$
q_{S j}^{*}=\frac{\alpha_{j}^{2}}{3 \alpha_{j}+2 \beta_{j} b}, q_{N j}^{*}=\frac{\alpha_{j}\left(\alpha_{j}+\beta_{j} b\right)}{3 \alpha_{j}+2 \beta_{j} b},
$$

and the equilibrium prices under the American regulation:

$$
p_{j}^{U A}=\frac{\left(\alpha_{j}+\beta_{j} b\right)}{3 \alpha_{j}+2 \beta_{j} b}, j=1,2 .
$$

From these equilibrium prices, we can derive two kind of conclusions. First, the prices across zones are different. Second, in each zone there is a strategic link between the $\mathrm{U}$ and $\mathrm{R}$ areas that makes the equilibrium prices to be higher than in a standard Cournot model. ${ }^{21}$ If we take the derivative of the price with respect to $\alpha_{j}$ and $\beta_{j}$, we see that it is negative with respect to the former and positive with respect to the latter. This shows that the strategic link within a zone is stronger when the relative weight of the $\mathrm{R}$ area becomes larger. This is so because the firm $S$, which operates in both areas, is more interested in relaxing competition in the $\mathrm{U}$ area the larger is the $\mathrm{R}$ area that it can be monopolized. The question that remains unanswered is how should the areas be to obtain the maximum possible social welfare.

Proposition $1 A$ regulator must set $\alpha_{j}=\beta_{j}$ to maximize social welfare under both $S W_{1}$ and $S W_{2}$.

The implications of proposition 1 are several. First, it establishes that the $\mathrm{R}$ market must be divided so as to replicate the division of the $\mathrm{U}$ market. Consequently, the size of the $\mathrm{U}$ market areas must be taken into account when deciding upon the division of the $\mathrm{R}$ market. Second, at the optimal division, prices do not vary across geographical zone. More precisely, at $\alpha_{j}=\beta_{j}$, we have $p_{1}^{U A}=p_{2}^{U A}=p_{1}^{R}=p_{2}^{R} \cdot{ }^{22}$

We turn now to analyze the implications of the European Council definition of affordable prices. This definition advocates for a common price in the whole country. ${ }^{23}$ This definition is more restrictive, because it adds

\footnotetext{
${ }^{21}$ The existence of this strategic link is shown in Anton et al. (2002) and Valletti et al. (2002).

${ }^{22}$ Therefore, the set-ups analyzed in papers as Anton et al. (2002) or Valletti et al. (2002) are optimal under the American Regulation.

${ }^{23}$ For further details, see Directive 2002/22/CE of the European Parliament and the Council.
} 
to the American definition a new constraint. This new constraint consists in forcing zone 1 to set the same price than zone 2. In principal, this opens two possibilities, depending on whether the regulator can decide on the size of the areas of the $\mathrm{U}$ and $\mathrm{R}$ markets or not. If the regulator can decide $\alpha_{1}$ and $\beta_{1}$ the regulation can be trivially fulfilled without affecting the firms decisions. But, if on the contrary, $\alpha_{1}$ and $\beta_{1}$ are given, then the European regulation may have a bite on welfare. In what follows we analyze these two cases.

Proposition 2 If $\frac{\alpha_{1}}{\beta_{1}}=1$, zone 1 and the zone 2 enjoy the same price than under the American definition.

If $\alpha_{1}=\beta_{1}$, the strategic link between the area 1 of the $\mathrm{U}$ market and area 1 of the $\mathrm{R}$ market is as strong as the strategic link between the area 2 of the $\mathrm{U}$ market and area 2 of the $\mathrm{R}$ market. This gives raise to equal prices in both zones.

The most likely situation for a regulator is that she cannot decide the size of the areas of the $\mathrm{U}$ and $\mathrm{R}$ markets. ${ }^{24}$ In this case, if the regulator does not impose a new restriction on the firms, the prices in both zones would be different as it was shown when analyzing the American definition.

Proposition 3 If $\frac{\alpha_{1}}{\beta_{1}} \neq 1$, the regulator introduces the price-cap $p_{j}^{U E} \leq$ $\min \left\{P_{1}^{U A}, P_{2}^{U A}\right\}, j=1,2$ to ensure the same price for the whole country.

Note that $p_{1}^{U A}$ and $p_{2}^{U A}$ are the equilibrium prices that firms would choose if they were under the American definition of affordable prices, whereas $p_{j}^{U E}$ is the price under the European Regulation in area 1 and 2 of the $U$ market. The regulator needs to impose this new price-cap to ensure that the prices within the zones 1 and 2 are the same. One may think that other common prices for the country are possible by using another kind of price cap as it may be a convex combination of $p_{1}^{U}$ and $p_{2}^{U}$ or even the maximum of both prices. But, under either possibility, prices across zones will not be equal.

There is another alternative to ensure a unique price in the whole country. This alternative consists in the regulator setting directly the price but we do not consider it because it is too intrusive.

The remaining question that we now try to answer is which definition brings the highest social welfare. The ranking is unambiguous under either measure of social welfare. This is the content of next proposition

\footnotetext{
${ }^{24}$ There are very little chances for a regulator of diving the country as she wishes due to either political or physical reasons.
} 
Proposition 4 The European definition brings higher social welfare than the American definition.

The intuition behind Proposition 4 is straightforward. We show in Proposition 3 that the European definition is implemented using the prices derived under the American definition and adding a new price-cap. This price-cap forces to lower the price in the zone where it was higher, keeping constant the lowest price. So, at the end of the day, with the European definition there is a zone where the price is the same as in the American definition, and a zone where the price is lower, what means that the social welfare is higher under the European definition.

\section{An alternative definition (I): a common price for the $\mathbf{R}$ market}

We introduce a new definition of affordable price. We propose that all consumers in the whole $\mathrm{R}$ market have to pay the same price regardless of the geographic zone where they live. In other words, areas 1 and 2 of the $\mathrm{R}$ market share the same price. We will model this definition by imposing a price cap on the price in the $\mathrm{R}$ market, so that $p^{R}$ cannot be larger than the convex combination of the prices in the $\mathrm{U}$ areas, that is $p^{R} \leq \theta p_{1}^{U}+(1-\theta) p_{2}^{U}$, $\theta \in[0,1] .^{25}$

As in the other cases, we introduce this definition into our game in the third stage. In addition, we now need to add up a new stage prior to the first stage of the primitive game, where a regulator decides about the value of $\theta$ in order to maximize social welfare. ${ }^{26}$ Once we have defined the game, we solve it using backward induction. As in the previous cases, it is also straightforward to see that the constraint $p^{R} \leq \theta p_{1}^{U}+(1-\theta) p_{2}^{U}$ will be binding in equilibrium. The monopoly prices in the areas of the $\mathrm{R}$ market are higher than the convex combination of the equilibrium prices in the areas of the $\mathrm{U}$ market. Thus $p^{R}=\theta p_{1}^{U}+(1-\theta) p_{2}^{U}$.

\footnotetext{
${ }^{25}$ This definition tries to capture the regulatory police on USOs by OFTEL. In July 1997, OFTEL established the level of Universal Service for the 4 year period from 1997 to 2001 as comprising the provision of universal services at "geographically averaged prices.".

${ }^{26} \mathrm{It}$ is worthy to point out that the equilibrium prices in the areas of the U market may be different across zones under this definition.
} 
Once the price in the $\mathrm{R}$ market is determined, we solve for the equilibrium quantities in the $\mathrm{U}$ market areas. Recall that the prices in the $\mathrm{U}$ market are:

$$
p_{j}^{U}=1-\frac{\left(q_{S j}+q_{N j}\right)}{\alpha_{j}}, j=1,2 .
$$

Therefore, profits for the firm that operates in both areas of zone 1 are:

$$
\begin{gathered}
\Pi_{S 1}=\left(1-\frac{\left(q_{S 1}+q_{N 1}\right)}{\alpha_{1}} q_{S 1}\right)+ \\
\left(1-\left(\frac{\theta\left(q_{S 1}+q_{N 1}\right)}{\alpha_{1}}+\frac{(1-\theta)\left(q_{S 2}+q_{N 2}\right)}{\alpha_{2}}\right)\right) b \beta_{1}\left(\frac{\theta\left(q_{S 1}+q_{N 1}\right)}{\alpha_{1}}+\frac{(1-\theta)\left(q_{S 2}+q_{N 2}\right)}{\alpha_{2}}\right) \\
-F_{1}^{R}-F_{1}^{U}+s_{1} .
\end{gathered}
$$

Profits for the firm that only operates in the $\mathrm{U}$ area of zone 1 are:

$$
\Pi_{N 1}=\left(1-\frac{\left(q_{S 1}+q_{N 1}\right)}{\alpha_{1}}\right) q_{N 1}-F_{1}^{U} .
$$

Profits for the firm that operates in both areas of zone 2 are:

$$
\begin{gathered}
\Pi_{S 2}=\left(1-\frac{\left(q_{S 2}+q_{N 2}\right)}{\alpha_{2}}\right) q_{S 2}+ \\
\left(1-\left(\frac{\theta\left(q_{S 1}+q_{N 1}\right)}{\alpha_{1}}+\frac{(1-\theta)\left(q_{S 2}+q_{N 2}\right)}{\alpha_{2}}\right)\right) b \beta_{2}\left(\frac{\theta\left(q_{S 1}+q_{N 1}\right)}{\alpha_{1}}+\frac{(1-\theta)\left(q_{S 2}+q_{N 2}\right)}{\alpha_{2}}\right) \\
-F_{2}^{R}-F_{2}^{U}+s_{2} .
\end{gathered}
$$

Finally, profits for the firm that only operates in the $U$ area of zone 2 are:

$$
\Pi_{N 2}=\left(1-\frac{\left(q_{S 2}+q_{N 2}\right)}{\alpha_{2}}\right) q_{N 2}-F_{1}^{U} .
$$

We maximize the profits of all firms with respect to their respective quantities. The reaction functions we obtain from the maximization problems yield the following equilibrium quantities: 


$$
\begin{aligned}
& q_{S 1}^{* *}=\frac{\alpha_{1}\left(\alpha_{1}\left(3 \alpha_{2}+3 b \beta(1-\theta)^{2}\right)-2 \alpha_{2} b \beta_{1}(1-\theta) \theta\right)}{\left.\left.3\left(\alpha_{1}\left(3\left(1-\alpha_{1}\right)+2 b\left(1-\beta_{1}\right)(1-\theta)^{2}\right)\right)+2\left(1-\alpha_{1}\right) b \beta_{1} \theta^{2}\right)\right)}, \\
& q_{N 1}^{* *}=\frac{\alpha_{1}\left(\alpha_{1}\left(3 \alpha_{2}+2 b \beta_{2}(1-\theta)^{2}\right)+\alpha_{2} b \beta_{1} \theta(1+2 \theta)\right)}{\left.\left.3\left(\alpha_{1}\left(3\left(1-\alpha_{1}\right)+2 b\left(1-\beta_{1}\right)(1-\theta)^{2}\right)\right)+2\left(1-\alpha_{1}\right) b \beta_{1} \theta^{2}\right)\right)}, \\
& q_{S 2}^{* *}=\frac{\alpha_{2}\left(2 \alpha_{2} b \beta_{1} \theta^{2}+3 \alpha_{1} \alpha_{2}-\alpha_{1}\left(2 b \beta_{2}(1-\theta) \theta\right)\right)}{\left.\left.3\left(\alpha_{1}\left(3\left(1-\alpha_{1}\right)+2 b\left(1-\beta_{1}\right)(1-\theta)^{2}\right)\right)+2\left(1-\alpha_{1}\right) b \beta_{1} \theta^{2}\right)\right)}, \\
& q_{N 2}^{* *}=\frac{\alpha_{2}\left(2 \alpha_{2} b \beta_{1} \theta^{2}+\alpha_{1}\left(3 \alpha_{2}+b \beta_{2}\left(3-5 \theta+2 \theta^{2}\right)\right)\right)}{\left.\left.3\left(\alpha_{1}\left(3\left(1-\alpha_{1}\right)+2 b\left(1-\beta_{1}\right)(1-\theta)^{2}\right)\right)+2\left(1-\alpha_{1}\right) b \beta_{1} \theta^{2}\right)\right)}
\end{aligned}
$$

and the equilibrium prices:

$$
\begin{gathered}
p_{1}^{U}=\frac{\alpha_{1}\left(3 \alpha_{2}+2 b \beta_{2}(1-\theta)^{2}\right)+\alpha_{2} b \beta_{1} \theta(1+2 \theta)}{3\left(\alpha_{1}\left(3 \alpha_{2}+2 b \beta_{2}(1-\theta)^{2}\right)+2 \alpha_{2} b \beta_{1} \theta^{2}\right)}, \\
p_{2}^{U}=\frac{\alpha_{1}\left(\alpha_{2}+b \beta_{2}\left(3-5 \theta+2 \theta^{2}\right)\right)+2 \alpha_{2} b \beta_{1} \theta^{2}}{3\left(\alpha_{1}\left(3 \alpha_{2}+2 b \beta_{2}(1-\theta)^{2}\right)+2 \alpha_{2} b \beta_{1} \theta^{2}\right)} \\
p^{R}=\frac{\left.\alpha_{1}\left(\alpha_{2}+b \beta_{2}(1-\theta)^{2}\right)+\alpha_{2} b \beta_{1} \theta^{2}\right)}{3\left(\alpha_{1}\left(3 \alpha_{2}+2 b \beta_{2}(1-\theta)^{2}\right)+2 \alpha_{2} b \beta_{1} \theta^{2}\right)} .
\end{gathered}
$$

Finally, given the equilibrium prices and quantities, the regulator chooses $\theta$ so that the social welfare is maximized. Next proposition characterizes the regulator choices under $S W_{1}$.

Proposition 5 Under $S W_{1}$, for a given $\alpha_{1}$ and $b$, in the unique subgame perfect equilibrium, the regulator chooses:

1. $\theta^{*}=1$, for all $\beta_{1} \in\left[0, \underline{\beta}_{1} 1\right]$

2. $\theta^{*}=0$, for all $\beta_{1} \in\left[\bar{\beta}_{1}, 1\right]$

3. $\theta^{*} \in(0,1)$, for all $\beta_{1} \in\left[\underline{\beta}_{1}, \bar{\beta}_{1}\right]$ 
where $\beta_{1}$ is an increasing function on $\alpha_{1}$ and $b$, and $\bar{\beta}_{1}$ is an increasing function on $\alpha_{1}$ and decreasing on $b$.

To analyze deeply the implications of this new definition we focus on three cases: $\theta^{*}=0, \theta^{*}=1$ and $\theta^{*}=\frac{1}{2}$. We only study these three cases for two reasons. First, because $\theta^{*}=0, \theta^{*}=1$ are the most likely equilibria. Second, we have also chosen $\theta^{*}=\frac{1}{2}$ as a representation of an interior equilibria because if we consider all possible equilibria, the analysis becomes rather complex as to allow us to get any conclusive result.

Note that, in equilibrium, this definition of affordable prices can be easily redefined when we consider only the equilibria $\theta^{*}=0$ and $\theta^{*}=1$, either as $p^{R}=\min \left\{p_{1}^{U A}, p_{2}^{U A}\right\}$ or as $p^{R}=\max \left\{p_{1}^{U A}, p_{2}^{U A}\right\} .{ }^{27}$

Without lost of generality, we suppose that $\min \left\{p_{1}^{U A}, p_{2}^{U A}\right\}=p_{1}^{U A}$, or equivalently, $\min \left\{\frac{\beta_{1}}{\alpha_{1}}, \frac{\beta_{2}}{\alpha_{2}}\right\}=\frac{\beta_{1}}{\alpha_{1}}$. In this case, if the regulator wishes to set $p^{R}$ as $\min \left\{p_{1}^{U A}, p_{2}^{U A}\right\}$, he would choose $\theta^{*}=1$. This means that the profits of the firm that operates in both areas of zone 1 are given by:

$$
\Pi_{S 1}=\left(1-\frac{\left(q_{S 1}+q_{N 1}\right)}{\alpha_{1}}\right)\left(q_{S 1}+\frac{\beta_{1} b\left(q_{S 1}+q_{N 1}\right)}{\alpha_{1}}\right)-F_{1}^{U}-F_{1}^{R}+s_{1},
$$

and for the firm that operates only in the urban area of zone 1 are:

$$
\Pi_{N 1}=\left(1-\frac{\left(q_{S 1}+q_{N 1}\right)}{\alpha_{1}}\right) q_{N 1}-F_{1}^{U} .
$$

These profit functions are identical to those under the American definition of affordable prices.

We turn now to analyze zone 2 . In this case, the profit function of the firm that operates in both areas is:

$$
\begin{gathered}
\Pi_{S 2}=\left(1-\frac{\left(q_{S 2}+q_{N 2}\right)}{\alpha_{2}}\right) q_{S 2}+ \\
+\left(1-\frac{\left(q_{S 1}+q_{N 1}\right)}{\alpha_{1}}\right)\left(\frac{\beta_{2} b\left(q_{S 1}+q_{N 1}\right)}{\alpha_{1}}\right)-F_{2}^{U}-F_{2}^{R}+s_{2},
\end{gathered}
$$

and for the firm that operates only in the area 2 of the $\mathrm{U}$ market:

\footnotetext{
${ }^{27}$ Recall that the prices $p_{1}^{U A}$ and $p_{2}^{U A}$ are the equilibrium prices under the American definition.
} 


$$
\Pi_{N 2}=\left(1-\frac{\left(q_{S 2}+q_{N 2}\right)}{\alpha_{2}}\right) q_{N 2}-F_{2}^{U}
$$

If we look at the profit functions, we can see that firm S2 profit function depends upon quantities $q_{S 1}$ and $q_{N 1}$. Taking into account this fact, the maximization problem reduces to a symmetric Cournot problem where only area 2 of the $\mathrm{U}$ market matters. This means that consumers in area 2 of the $\mathrm{U}$ market enjoy a lower price. To summarize, the $\mathrm{R}$ market and area 1 of the $\mathrm{U}$ market share the same price which is $p_{1}^{U A}$. Firms in the area 2 of the $\mathrm{U}$ area set the symmetric Cournot price which is lower. ${ }^{28}$

We can make a similar analysis for the case where $p^{R}=\max \left\{p_{1}^{U A}, p_{2}^{U A}\right\}$, so that $p^{R}=\max \left\{\frac{\beta_{1}}{\alpha_{1}}, \frac{\beta_{2}}{\alpha_{2}}\right\}$. If we suppose that $\max \left\{p_{1}^{U A}, p_{2}^{U A}\right\}=p_{2}^{U A}$, in equilibrium, firms in the $\mathrm{R}$ market and in the area 1 of the $\mathrm{U}$ area set an equal price which is higher than the symmetric Cournot price which is set in the area 2 of the $\mathrm{U}$ market. ${ }^{29}$

Now, we analyze under what conditions a regulator decides to choose $p^{R}=\max \left\{p_{1}^{U A}, p_{2}^{U A}\right\}\left(\theta^{*}=0\right)$ instead of $p^{R}=\min \left\{p_{1}^{U A}, p_{2}^{U A}\right\}\left(\theta^{*}=1\right)$ or the equilibrium price that comes out from $\theta^{*}=\frac{1}{2}$.

We analyze first when the regulator chooses $p^{R}=\max \left\{p_{1}^{U A}, p_{2}^{U A}\right\}$ instead of $p^{R}=\min \left\{p_{1}^{U A}, p_{2}^{U A}\right\}$. At first sight, we may think that a regulator should always choose $p^{R}=\min \left\{p_{1}^{U A}, p_{2}^{U A}\right\}$, because it ensures the minimum price for three out of the four areas, and in addition, the remaining area enjoys the symmetric Cournot price. This may be a reasonable argument, but it is not always right. For example, one can imagine an scenario where the opposite holds. Consider a situation as the one described graphically in the figure 3 of the appendix. For this case $\alpha_{1}<\alpha_{2}$, and $\alpha_{1}<\beta_{1}<\beta_{2}$. In this scenario $p_{1}^{U A}>p_{2}^{U A}$, but $p_{1}^{U A}-p_{2}^{U A}$ can be arbitrarily small. If the regulator chooses the minimum prices then $p^{R}=p_{2}^{U A}=p_{2}^{U}$ and $p_{1}^{U}=p^{C}$, if the regulator chooses the maximum prices then $p^{R}=p_{1}^{U A}=p_{1}^{U}$ and $p_{2}^{U}=p^{C}$, where $p^{C}$ is the symmetric Cournot price.

If the regulator chooses $p_{1}^{U A}$, she gets the symmetric Cournot price for the area 2 of the $\mathrm{U}$ market, which is much larger than the area 1 of the $\mathrm{U}$ market. Thus, the regulator prefers to set $p^{R}=\max \left\{p_{1}^{U A}, p_{2}^{U A}\right\}$, because the loss in social welfare in the whole $\mathrm{R}$ market and in area 1 of the $\mathrm{U}$ market is more than overcome by the price drop in the area 2 of the $\mathrm{U}$ market.

\footnotetext{
${ }^{28}$ Even though $p_{2}^{U}<p_{1}^{U}=p_{1}^{U A}=p^{R}$, it is still true that $p_{2}^{U A} \geq p_{1}^{U A}$

${ }^{29}$ Now $p^{R}=p_{2}^{U A}=p_{2}^{U} \geq p_{1}^{U A}>p_{1}^{U}$
} 
This example has shown that the optimal decision may involve to choose the maximum price. To analyze this issue further, assume without loss of generality that the area 1 of the $\mathrm{R}$ market is always bigger than the area 1 of the $\mathrm{U}$ market, so that $\alpha_{1}<\beta_{1}{ }^{30}$ Then, a regulator chooses $\max \left\{p_{1}^{U A}, p_{2}^{U A}\right\}$ when the following condition holds:

$$
\alpha_{1} p^{C}+\alpha_{2} p_{1}^{U A}+b p_{1}^{U A}<\alpha_{1} p_{2}^{U A}+\alpha_{2} p^{C}+b p_{2}^{U A} .
$$

This condition means that a regulator chooses $\max \left\{p_{1}^{U A}, p_{2}^{U A}\right\}$ instead of $\min \left\{p_{1}^{U A}, p_{2}^{U A}\right\}$ when the sum of the prices, weighted by the size of the areas where they are set, is lower under $\max \left\{p_{1}^{U A}, p_{2}^{U A}\right\} .{ }^{31}$ If we operate the latter condition, we obtain that it can be written as:

$$
\frac{\alpha_{1}+b}{\alpha_{2}+b}<\frac{\beta_{2}\left(3 \alpha_{1}+2 \beta_{1} b\right)}{\beta_{1}\left(3 \alpha_{2}+2 \beta_{2} b\right)} .
$$

Choosing between $\min \left\{p_{1}^{U A}, p_{2}^{U A}\right\}$ and $\max \left\{p_{1}^{U A}, p_{2}^{U A}\right\}$ depends only on the values taken by $\alpha_{1}, \beta_{1}$ and $\mathrm{b}$. This fact allow us to plot when regulator chooses either $\max \left\{p_{1}^{U A}, p_{2}^{U A}\right\}$ or $\min \left\{p_{1}^{U A}, p_{2}^{U A}\right\}$. We can see the result in the graph in figure 2 .

Before we analyze the graph, let us explain the role of the curved lines. They can be interpreted as "level curves". Each one has an associated level of $b$. For instance, if we take the curved line associated to $b=4$, we know that for the pairs $\left(\alpha_{1}, \beta_{1}\right)$ in the level curved if $b \in[4, \infty)$ a regulator chooses $\max \left\{p_{1}^{U A}, p_{2}^{U A}\right\}$, and if $b \in[0,4)$, he chooses $\min \left\{p_{1}^{U A}, p_{2}^{U A}\right\}$. The first curved line does not have any associated $b$. From this curved line upwards, up to the line where $\alpha_{1}=\beta_{1}$, a regulator always chooses maximum no matter how big is the $\mathrm{R}$ market.

The first important issue is why a regulator always chooses $\min \left\{p_{1}^{U A}, p_{2}^{U A}\right\}$ whenever $\alpha_{1}>\frac{1}{2}{ }^{32}$ The reason is quite simple, he chooses so because if she takes $\max \left\{p_{1}^{U A}, p_{2}^{U A}\right\}$ the social welfare is reduced for two reasons. First, the $\mathrm{U}$ market area where the symmetric Cournot price is set is the smallest. Second, the price in the whole $\mathrm{R}$ market and in the other $\mathrm{U}$ market area is higher.

\footnotetext{
${ }^{30}$ This condition implies that $\max \left\{p_{1}^{U A}, p_{2}^{U A}\right\}=p_{1}^{U A}$ and $\min \left\{p_{1}^{U A}, p_{2}^{U A}\right\}=p_{2}^{U A}$. The results for the case when $\alpha_{1}>\beta_{1}$ are symmetric to the result found when $\alpha_{1}<\beta_{1}$ with respect to the point $\left(\alpha_{1}=0.5, \beta_{1}=0.5\right)$.

${ }^{31}$ In this case, looking for the minimum weighted price is equivalent to look for the highest social welfare, because $\alpha_{1}, \beta_{1}$ and $b$ are given.

${ }^{32}$ Recall that when $\alpha_{1}>\frac{1}{2}, \beta_{1}>\frac{1}{2}$ too.
} 
On the other hand, we find a region where a regulator always sets a price equal to $\max \left\{p_{1}^{U A}, p_{2}^{U A}\right\}$. This region starts in the line where $\alpha_{1}=\beta_{1}$, and continues downwards until the first curved line is reached. If we take the extreme case, $\alpha_{1} \rightarrow \beta_{1}$, we easily see that the social welfare is always higher when the regulator takes $\max \left\{p_{1}^{U A}, p_{2}^{U A}\right\}$. The symmetric Cournot price is in the largest $U$ market area, while the increase in the price of the other three areas is negligible. The same occurs in the whole region, although the preference for $\max \left\{p_{1}^{U A}, p_{2}^{U A}\right\}$ becomes weaker as we move towards the curved line. This region is wider when $\alpha_{1}$ is about $\frac{1}{4}$. This is because, as $\alpha_{1}$ goes to $\frac{1}{2}$ the gains from setting the symmetric Cournot price in the area 2 of the $U$ market decrease and at the same time, the losses in the other areas increase.

Finally, the region that goes from the curved line we have referred in the paragraph above to the line $\beta_{1}=\frac{1}{2}$ is the region where, depending on the size of the $\mathrm{R}$ market, a regulator chooses either $\min \left\{p_{1}^{U A}, p_{2}^{U A}\right\}$ or $\max \left\{p_{1}^{U A}, p_{2}^{U A}\right\}$. It is important to point out that the value of $b$ needed for making the minimum the optimal choice decreases as $\beta_{1}$ gets close to $1 / 2$. For fixed $\alpha_{1}$, when $\beta_{1} \rightarrow \frac{1}{2}$ the loss in social welfare of shifting from $\min \left\{p_{1}^{U A}, p_{2}^{U A}\right\}$ to $\max \left\{p_{1}^{U A}, p_{2}^{U A}\right\}$ is very high because the increment in the price is very significant.

To end the discussion on the regulator optimal choice for $\theta$, we introduce now into our analysis the choice $\theta^{*}=\frac{1}{2}$. Then the regulator has three possible choices: $\theta^{*}=0, \theta^{*}=1$ and $\theta=\frac{1}{2}$. When $\theta^{*}=\frac{1}{2}$, the price in the $\mathrm{R}$ market takes an intermediate value between the prices from $\theta^{*}=0$ and $\theta^{*}=1$. Therefore the regulator chooses $\theta^{*}=\frac{1}{2}$ in the regions where, in the previous analysis, she shifts her choice from $\theta^{*}=1$ to $\theta^{*}=0$. For example, if we take the case where $\alpha_{1}=\beta_{1}$, we know that if the regulator can only choose between $\theta^{*}=1$ and $\theta^{*}=0$, he shifts from $\theta^{*}=1$ to $\theta^{*}=0$ when $\beta_{1}=\frac{1}{2}$. But, if we introduce the possibility for the regulator of choosing $\theta^{*}=\frac{1}{2}$, there will be a segment including $\beta_{1}=\frac{1}{2}$ where the regulator chooses $\theta^{*}=\frac{1}{2}$.

We observe that for a given $b$, it is more likely that $\theta^{*}=\frac{1}{2}$ is chosen when both, $\alpha_{1}$ and $\beta_{1}$, are close to either $\frac{1}{2}$ or zero. As one of them is close to zero or 1 and the other takes intermediate values, it is more likely that the regulator is only interested in choosing $\theta^{*}=1$, i.e. $p^{R}=\max \left\{p_{1}^{U A}, p_{2}^{U A}\right\}$.

To conclude this discussion, we now study if this definition is superior to the the American and European definitions of affordable prices. 
Proposition 6 Under $S W_{1}$, if a regulator sets prices $p^{R} \leq \theta p_{1}^{U}+(1-\theta) p_{2}^{U}$, the social welfare is higher than under the American and European definition of affordable prices.

If we think about what happens when a regulator chooses $\min \left\{p_{1}^{U A}, p_{2}^{U A}\right\}$, we see that in one of the areas of the $\mathrm{U}$ market and in the whole $\mathrm{R}$ market the $\min \left\{p_{1}^{U A}, p_{2}^{U A}\right\}$ is set, the same happens to theses areas when the European definition is applied. But, in the other area of the $\mathrm{U}$ market, with the definition we propose, the symmetric Cournot price is set instead of the $\min \left\{p_{1}^{U A}, p_{2}^{U A}\right\}$, which would be set under the European definition. ${ }^{33}$ As the symmetric Cournot price is lower, the social welfare improves under the new definition. Given this, and taken into account that a regulator only chooses his other possible options for $\theta$ when they give larger social welfare than $\min \left\{p_{1}^{U A}, p_{2}^{U A}\right\}$, we can conclude that the new definition is superior to the American and the European definition of affordable prices.

We turn now to study the regulator choice under $S W_{2}$.

Proposition 7 Under $S W_{2}$, for a given $\alpha_{1}$ and $b$, in the unique subgame perfect equilibrium, the regulator chooses:

$$
\theta^{* *}=\frac{\alpha_{1}\left(1-\beta_{1}\right)}{\left(1-\alpha_{1}\right) \beta_{1}+\alpha_{1}\left(1-\beta_{1}\right)} .
$$

When the second definition is at work, she only takes interior values for $\theta$, because she is not internalizing the $\mathrm{U}$ market consumers prices. By definition, the $\mathrm{U}$ market prices are one higher and the other lower than the $\mathrm{R}$ market price. Thus, when the $\mathrm{R}$ market is not very large, the regulator is interesting in setting the Cournot price in the largest $U$ market area, what is very often achieved choosing a corner solution. Either $\theta=0$ or $\theta=1$. By contrast, under $S W_{2}$ no area of the $\mathrm{R}$ market can hold the Cournot price, making $\theta \in(0,1)$ the optimal choice, see figure 6 .

Regarding the comparison with the European and American definitions of affordable prices, it is easy to see that this definition is superior from a welfare viewpoint. As the regulator takes always interior solution for $\theta$, this means that she always chooses a better choice than $\min \left\{p_{1}^{U A}, p_{2}^{U A}\right\}$ (either $\theta=0$ or $\theta=1$ ), because it is an available option for her and he does not choose it.

\footnotetext{
${ }^{33}$ We refer only to the European definition, because we have proved that the European definition is superior in terms of social welfare to the American definition.
} 


\section{An alternative definition (II): yardstick pric- ing}

We introduce a second new definition of affordable prices. We propose that the price in any of the $\mathrm{R}$ market areas has to be lower or equal than a function of the prices in the $U$ market areas excluding the price of the $U$ market area it is attached to. ${ }^{34}$ If we apply this definition to our model, the price of the areas 1 and 2 of the $\mathrm{R}$ market cannot be higher than the price in the areas 2 and 1 of the $\mathrm{U}$ market respectively, $p_{j}^{R} \leq p_{k}^{U}$, for $j=1$, 2 , such that $k \neq j .{ }^{35}$

Once we have described our new definition of prices for the $\mathrm{R}$ market areas, we introduce it into our game in the third stage and we start solving the game by backward induction. So, first, we figure out the prices set by the firms for the different areas of the $\mathrm{R}$ market. The constraint $p_{j}^{R} \leq p_{k}^{U}$, for $j=1,2$ such that $k \neq j$ is binding in equilibrium. The monopoly price in any $\mathrm{R}$ market area is always higher than the equilibrium prices of any $\mathrm{U}$ market area. Thus, $p_{j}^{R}=p_{k}^{U}, k \neq j$.

The second stage is to find the equilibrium quantities in the $U$ market areas. The prices in the $\mathrm{U}$ market areas are determined by:

$$
p_{j}^{U}=\left(1-\frac{\left(q_{S j}+q_{N j}\right)}{\alpha_{j}}\right), j=1,2 .
$$

Given this and $p_{j}^{R}=p_{k}^{U}$ for $j=1,2$, such that $k \neq j$, the profits of the firms that operate in both areas $j$ of the $\mathrm{U}$ and $\mathrm{R}$ markets are:

$$
\begin{gathered}
\Pi_{1 j}=\left(1-\frac{\left(q_{S j}+q_{N j}\right)}{\alpha_{j}}\right) q_{S j}+ \\
+\left(1-\left(\frac{\left(q_{S k}+q_{N k}\right)}{\alpha_{k}}\right)\right)\left(\frac{\beta_{j} b\left(q_{S k}+q_{N k}\right)}{\alpha_{k}}\right)-F_{j}^{U}-F_{j}^{R}+s_{j}, \\
j=1,2, k \neq j .
\end{gathered}
$$

\footnotetext{
${ }^{34}$ This definition is inspired in the concept of "yardstick competition", as defined in Shleifer (1985).

${ }^{35}$ If we extend our model to $N$ areas in the $\mathrm{R}$ and $\mathrm{U}$ markets, $p_{j}^{R} \leq$ $f\left(p_{1}^{U}, \ldots, p_{j-1}^{U}, p_{j+1}^{U}, \ldots P_{N}^{U}\right), j=1, \ldots, N$. The most likely functional form for $f($.$) would$ be the sample mean of all prices expect $p_{j}^{U}$.
} 
The profits of the firms that only operate in the areas of the U market are:

$$
\Pi_{N j}=\left(1-\frac{\left(q_{S j}+q_{N j}\right)}{\alpha_{j}}-c\right) q_{N j}-F_{j}^{U}, j=1,2 .
$$

Given all profit functions, if we maximize them, we obtain the following result:

Proposition 8 Under yardstick pricing, the symmetric Cournot price, $p^{C}=$ $\frac{1}{3}$, is set in the whole $R$ and $U$ markets.

With this new regulation, we can set the lowest possible price in the whole country, given that firms compete a la Cournot in their respective areas of the $\mathrm{U}$ market. We have reached such a good result for the social welfare because we were able to break the strategic link that the American and the European definition of affordable prices create between the areas of the $\mathrm{U}$ and $\mathrm{R}$ markets. This strategic link made the equilibrium prices higher than the symmetric Cournot price. ${ }^{36}$

This regulatory regime has a negative aspect. In order to be worthy to apply it, we need that the differences in demand between the different zones of the country be small enough. For example, consider a situation where the demands in areas 1 and 2 of the $\mathrm{U}$ market are $D_{1}^{U}(p)=1-p$ and $D_{2}^{U}(p)=(a-p)$ the demand in area 1 and 2 of the $\mathrm{R}$ market are $D_{1}^{R}(p)=b(1-p)$ and $D_{2}^{R}(p)=b(a-p)$ where $a<1 .^{37}$ If we apply the proposed definition, we find that the symmetric Cournot equilibrium for the area 1 of the $\mathrm{U}$ market is $p^{C}=\frac{1}{3}$, which is even bigger than the monopoly price in the area 2 of the $\mathrm{U}$ market if $a<\frac{2}{3} .{ }^{38}$

\section{Conclusions}

In this paper, we have analyzed different definitions of affordable prices under Universal Service Obligations focusing on their implications on social welfare.

\footnotetext{
${ }^{36}$ For further details, see Anton et al. (2002) or Valletti et al. (2002).

${ }^{37}$ This could describe a situation where the $\mathrm{R}$ market consumers are poorer than the $\mathrm{U}$ area consumers.

${ }^{38}$ This may happen in Spain or Italy if we divide the countries in such a way that the zone 1 is the northern half of the countries (richer) and zone 2 is the southern half of the countries (poorer).
} 
We have studied the different definitions under the assumption that a country is divided into independent zones. Each of these zones consists on a profitable and an unprofitable area.

We have studied first, the definition of affordable prices that come from the American and the European regulatory regimes. The American regulatory regime advocates for a common price within each zone, whereas the European regulatory regime advocates for a common price for the whole country. We have shown that these two definitions of affordable prices are equivalent when the zones are designed in such a way that the ratio between the demands of the areas within each zone is constant. If this does not happen, the European definition is social welfare superior to the American definition. This is because the European definition obliges to set a unique price in the country.

We have also presented two new definitions of affordable prices. In the first definition, the price in all the unprofitable markets is the same and it cannot be higher than a convex combination of the prices in the profitable areas. We have proved that this definition is always social welfare superior to the European definition, and by extension to the American. Under this definition, when the welfare function is the standard, in many cases, the regulator chooses the maximum or the minimum of the available prices to apply it to the unprofitable market. This implies that there are profitable areas which enjoy the symmetric Cournot price (the lowest in our context). In the other cases, the regulator chooses convex combinations of the unprofitable market areas prices. It may sound strange that when the regulator opts for the maximum, this definition can be superior to the European definition. This is so, because under some circumstances (when the total unprofitable demand is small compared to the total demand), the best for social welfare is to set the symmetric Cournot price to as many consumers as possible in the profitable market, and to do so, the regulator has to impose the maximum. When the welfare function is only the unprofitable consumers surplus, the regulator choices change and she only chooses convex combinations of the unprofitable market area prices. This is for two reasons. First, because the unprofitable market consumers enjoy different prices than the profitable market consumers, and second, because the regulator does not internalize the profitable market consumers surplus.

The other definition we have presented is what we denote "yardstick pricing". In this definition, the prices of the unprofitable areas can never be higher than a function of the prices of all profitable areas expect the price 
of its own zone profitable area. With this definition, we break the strategic link that firms use to raise the price. Thus, we can implement the symmetric Cournot price all over the country which yields the maximum social welfare. The problem with this last definition is that to work properly we need consumers' demands not to be very different between the different zones. For example, this definition can yield very bad results from a social point of view when the differences in income between zones are very high.

Given our results. National Regulatory Board should implement our first definition when differences in demand between markets are very large, and yardstick pricing when the differences are not significant. 


\section{References}

[1] Anton J.J., Vander J.H. and Vettas N. (2002). "Entry auctions and strategic behavior under cross-market price constraints. International Journal of Industrial Organization, vol 20, pp 611-629.

[2] Chone P., Flochel L. and Perrot A. (2000). "Universal service obligations and competition". Information Economics and Policy. vol 12(3). pp 249259.

[3] Chone P., Flochel L. and Perrot A. (2002). "Allocating and funding universal service obligations in a competitive market". International Journal of Industrial Organization. vol 20(9). pp 1247-1276.

[4] European Parliament and the Council of the European Union. (2002). "Directive 2002/22/CE"

[5] Federal Communication Commission (1996). "Telecommunication Act"

[6] Federal Communication Commission (1996). "In the matter of FederalState Joint Board on Universal Service". CC Docket no 96-47.

[7] Gasmi F., Laffont J.J. and Sharkey W.W. (2000). "Competition, universal service and telecommunication policy in developing countries". Infomation Economics and Policy, vol 12(3), pp 221-248.

[8] Iozzi. A. (2001). "Who gains from Universal Service Obligations? A welfare analysis of the rule 'One price for everywhere'". Studi Economici, vol 74(2), pp 131-152.

[9] Laffont J.J. and Tirole J. (2000). "Competition in Telecommunications". Cambridge, MA, MIT Press.

[10] Rosston G. and Bradley S. (2000). "The 'state' of universal service" Information Economics and Policy, vol 12(3), pp 261-283.

[11] Shleifer A. (1985). "A theory of yardstick competition" RAND Journal of Economics, vol 16(3), pp 319-327.

[12] Valletti T. (2000). "Introduction: Symposium on universal service obligation and competition" Information Economics and Policy, vol 12(3), pp 205-210. 
[13] Valletti T., Hoernig S. and Barros P.P. (2002). "Universal Service and Entry: The Role Of Uniform Pricing and Coverage Constraints". Journal of Regulatory Economics, vol 21(2), pp 169-190. 


\section{A appendix}

\section{A.1 Proof Proposition 1}

We first show the result under the proviso that the regulator maximizes $S W_{1}$. In this case, she chooses $\alpha_{1}$ and $\beta_{1}$ as to:

$$
\begin{gathered}
\max _{\alpha_{1}, \beta_{1}} S W_{1}\left(\alpha_{1}, \beta_{1}\right)=\left(\alpha_{1}+b \beta_{1}\right) \frac{\left(1-p_{1}^{U A}\left(\alpha_{1}, \beta_{1}\right)\right)^{2}}{2}+ \\
\left(\left(1-\alpha_{1}\right)+b\left(1-\beta_{1}\right)\right) \frac{\left(1-p_{2}^{U A}\left(\alpha_{1}, \beta_{1}\right)\right)^{2}}{2}+\left(\alpha_{1}+b \beta_{1}\right) p_{1}^{U A}\left(\alpha_{1}, \beta_{1}\right)\left(1-p_{1}^{U A}\left(\alpha_{1}, \beta_{1}\right)\right)+ \\
+\left(\left(1-\alpha_{1}\right)+b\left(1-\beta_{1}\right)\right) p_{2}^{U A}\left(\alpha_{1}, \beta_{1}\right)\left(1-p_{2}^{U A}\left(\alpha_{1}, \beta_{1}\right)\right),
\end{gathered}
$$

where the first two terms are consumers surplus and the remaining two terms are firms profits.

Now,

$$
p_{1}^{U A}\left(\alpha_{1}, \beta_{1}\right)=\frac{\alpha_{1}+\beta_{1} b}{3 \alpha_{1}+2 \beta_{1} b}
$$

is the price in area 1 of the $\mathrm{U}$ market under the American regulation, and

$$
p_{2}^{U A}\left(\alpha_{1}, \beta_{1}\right)=\frac{\left(1-\alpha_{1}\right)+\left(1-\beta_{1}\right) b}{3\left(1-\alpha_{1}\right)+2\left(1-\beta_{1}\right) b}
$$

is the price in area 2 of the $\mathrm{U}$ market under the American regulation.

Differentiating the social welfare function with respect to $\alpha_{1}$ and $\beta_{1}$ we have:

$$
\begin{aligned}
& \frac{\partial S W_{1}\left(\alpha_{1}, \beta_{1}\right)}{\partial \alpha_{1}}=\frac{\left(1-p_{1}^{U A}\left(\alpha_{1}, \beta_{1}\right)\right)^{2}}{2}-\left(\alpha_{1}+b \beta_{1}\right)\left(1-p_{1}^{U A}\left(\alpha_{1}, \beta_{1}\right)\right) \frac{\partial p_{1}^{U A}\left(\alpha_{1}, \beta_{1}\right)}{\partial \alpha_{1}}- \\
& \frac{\left(1-p_{2}^{U A}\left(\alpha_{1}, \beta_{1}\right)\right)^{2}}{2}-\left(\left(1-\alpha_{1}\right)+b\left(1-\beta_{1}\right)\right)\left(1-p_{2}^{U A}\left(\alpha_{1}, \beta_{1}\right)\right) \frac{\partial p_{2}^{U A}\left(\alpha_{1}, \beta_{2}\right)}{\partial \alpha_{1}}+ \\
& p_{1}^{U A}\left(\alpha_{1}, \beta_{1}\right)\left(1-p_{1}^{U A}\left(\alpha_{1}, \beta_{1}\right)\right)+\left(\alpha_{1}+b \beta_{1}\right)\left(\frac{\partial p_{1}^{U A}\left(\alpha_{1}, \beta_{1}\right)}{\partial \alpha_{1}}\left(1-p_{1}^{U A}\left(\alpha_{1}, \beta_{1}\right)\right)\right)-
\end{aligned}
$$




$$
\begin{gathered}
\left(\alpha_{1}+b \beta_{1}\right)\left(p_{1}^{U A}\left(\alpha_{1}, \beta_{1}\right) \frac{\partial p_{1}^{U A}\left(\alpha_{1}, \beta_{1}\right)}{\partial \alpha_{1}}\right)-p_{2}^{U A}\left(\alpha_{1}, \beta_{1}\right)\left(1-p_{2}^{U A}\left(\alpha_{1}, \beta_{1}\right)\right)+ \\
\left(\left(1-\alpha_{1}\right)+b\left(1-\beta_{1}\right)\right)\left(\frac{\partial p_{2}^{U A}\left(\alpha_{1}, \beta_{1}\right)}{\partial \alpha_{1}}\left(1-p_{2}\left(\alpha_{1}, \beta_{2}\right)\right)\right) \\
-\left(\left(1-\alpha_{1}\right)+b\left(1-\beta_{1}\right)\right)\left(p_{2}^{U A}\left(\alpha_{1}, \beta_{1}\right)\left(\frac{\partial p_{2}^{U A}\left(\alpha_{1}, \beta_{1}\right)}{\partial \alpha_{1}}\right)\right.
\end{gathered}
$$

and

$$
\begin{gathered}
\frac{\partial W\left(\alpha_{1}, \beta_{1}\right)}{\partial \beta_{1}}=b \frac{\left(1-p_{1}^{U A}\left(\alpha_{1}, \beta_{1}\right)\right)^{2}}{2}-\left(\alpha_{1}+b \beta_{1}\right)\left(1-p_{1}^{U A}\left(\alpha_{1}, \beta_{1}\right)\right) \frac{\partial p_{1}^{U A}\left(\alpha_{1}, \beta_{1}\right)}{\partial \beta_{1}} \\
-b \frac{\left(1-p_{2}^{U A}\left(\alpha_{1}, \beta_{1}\right)\right)^{2}}{2}-\left(\left(1-\alpha_{1}\right)+b\left(1-\beta_{1}\right)\right)\left(1-p_{2}^{U A}\left(\alpha_{1}, \beta_{1}\right)\right) \frac{\partial p_{2}^{U A}\left(\alpha_{1}, \beta_{2}\right)}{\partial \beta_{1}}+ \\
b p_{1}^{U A}\left(\alpha_{1}, \beta_{1}\right)\left(1-p_{1}^{U A}\left(\alpha_{1}, \beta_{1}\right)\right)+\left(\alpha_{1}+b \beta_{1}\right)\left(\frac{\partial p_{1}^{U A}\left(\alpha_{1}, \beta_{1}\right)}{\partial \beta_{1}}\left(1-p_{1}^{U A}\left(\alpha_{1}, \beta_{1}\right)\right)\right) \\
-\left(\alpha_{1}+b \beta_{1}\right)\left(p_{1}^{U A}\left(\alpha_{1}, \beta_{1}\right) \frac{\partial p_{1}^{U A}\left(\beta_{1}, \beta_{1}\right)}{\partial \beta_{1}}\right)-b p_{2}^{U A}\left(\alpha_{1}, \beta_{1}\right)\left(1-p_{2}^{U A}\left(\alpha_{1}, \beta_{1}\right)\right)+ \\
\left(\left(1-\alpha_{1}\right)+b\left(1-\beta_{1}\right)\right)\left(\frac{\partial p_{2}^{U A}\left(\alpha_{1}, \beta_{1}\right)}{\partial \beta_{1}}\left(1-p_{2}\left(\alpha_{1}, \beta_{2}\right)\right)\right) \\
-\left(\left(1-\alpha_{1}\right)+b\left(1-\beta_{1}\right)\right)\left(p_{2}^{U A}\left(\alpha_{1}, \beta_{1}\right)\left(\frac{\partial p_{2}^{U A}\left(\alpha_{1}, \beta_{1}\right)}{\partial \beta_{1}}\right) .\right.
\end{gathered}
$$

Both derivatives equal zero at $\alpha_{1}=\beta_{1}$. Since, further, the function is concave in both variables, see figure 5 , we can conclude that $\alpha_{1}=\beta_{1}$ are the maxima of the social welfare function. 
We now analyze the regulator choice when she maximizes $S W_{2}$. The programme she faces is to maximize

$$
b \beta_{1} \frac{\left(1-p_{1}^{U A}\left(\alpha_{1}, \beta_{1}\right)\right)^{2}}{2}+b\left(1-\beta_{1}\right) \frac{\left(1-p_{2}^{U A}\left(\alpha_{1}, \beta_{1}\right)\right)^{2}}{2},
$$

where the social welfare function is the sum of the consumers' surplus in the $\mathrm{R}$ market.

Differentiating the social welfare function with respect to $\alpha_{1}$ and $\beta_{1}$ we have:

$$
\begin{aligned}
& \frac{\partial S W_{2}\left(\alpha_{1}, \beta_{1}\right)}{\partial \alpha_{1}}=\beta_{1} b\left(1-p_{1}\left(\alpha_{1}, \beta_{1}\right)\right) \frac{\partial p_{1}\left(\alpha_{1}, \beta_{1}\right)}{\partial \alpha_{1}}+\left(1-\beta_{1}\right) b\left(1-p_{2}\left(\alpha_{1}, \beta_{1}\right)\right) \frac{\partial p_{2}\left(\alpha_{1}, \beta_{1}\right)}{\partial \alpha_{1}} \\
& \text { and } \\
& \frac{\partial S W_{2}\left(\alpha_{1}, \beta_{1}\right)}{\partial \beta_{1}}=b \frac{\left(1-p_{1}\left(\alpha_{1}, \beta_{1}\right)\right)^{2}}{2}+\beta_{1} b\left(1-p_{1}\left(\alpha_{1}, \beta_{1}\right)\right) \frac{\partial p_{1}\left(\alpha_{1}, \beta_{1}\right)}{\partial \beta_{1}} \\
& \qquad-b \frac{\left(1-p_{1}\left(\alpha_{1}, \beta_{1}\right)^{2}\right.}{2}+\left(1-\beta_{1}\right) b\left(1-p_{2}\left(\alpha_{1}, \beta_{1}\right)\right) \frac{\partial p_{2}\left(\alpha_{1}, \beta_{1}\right)}{\partial \beta_{1}} .
\end{aligned}
$$

As for the other social welfare function, both derivatives equal 0 at $\alpha_{1}=$ $\beta_{1}$. As the function is concave, $\alpha_{1}=\beta_{1}$ are maxima.

\section{A.2 Proof Proposition 2}

If $\frac{\alpha_{1}}{\beta_{1}}=1$ then $\frac{\alpha_{2}}{\beta_{2}}=1$ as well, as $\alpha_{1}+\alpha_{2}=1$ and $\beta_{1}+\beta_{2}=1$. Given the equilibrium prices under the American definition:

$$
p_{j}^{U A}=\frac{\left(\alpha_{j}+\beta_{j} b\right)}{3 \alpha_{j}+2 \beta_{j} b}, j=1,2
$$

The following condition has to hold in order to ensure that they are equal:

$$
\frac{\alpha_{1}+\beta_{1} b}{3 \alpha_{1}+2 \beta_{1} b}=\frac{\alpha_{2}+\beta_{2} b}{3 \alpha_{2}+2 \beta_{2} b} \text {. }
$$

Note that $\alpha_{1} / \beta_{1}=\alpha_{2} / \beta_{2}=1$ is a sufficient condition to guarantee that they are equal as:

$$
\frac{1+b}{3+2 b}=\frac{1+b}{3+2 b} \text {. }
$$




\section{A.3 Proof Proposition 3}

We know that the price-cap $p_{j}^{R} \leq p_{j}^{U}, j=1,2$ is binding in equilibrium. This means that within each zone, there is a unique price. If we introduce the price-cap $p_{j}^{U} \leq \min \left\{p_{1}^{U A}, p_{2}^{U A}\right\}$, we can guarantee that it is also binding in equilibrium by the definition of minimum. This means that both zones share the same prices.

\section{A.4 Proof Proposition 4}

The proof under $S W_{1}$ goes as follows: under the European definition, $\min \left\{p_{1}^{U A}, p_{2}^{U A}\right\}$ is applied to all areas of the $\mathrm{U}$ and $\mathrm{R}$ markets. Assuming without loss of generality that $\min \left\{p_{1}^{U A}, p_{2}^{U A}\right\}=p_{1}^{U A}$, the weighted price for the whole country becomes:

$$
\alpha_{1} p_{1}^{U A}+\alpha_{2} p_{1}^{U A}+\beta_{1} b p_{1}^{U A}+\beta_{2} p_{1}^{U A}
$$

Under the American definition zone 1 enjoys price $p_{1}^{U A}$ and zone 2 enjoys price $p_{2 A}^{U}$. Thus, the weighted price for the whole country is:

$$
\alpha_{1} p_{1}^{U A}+\alpha_{2} p_{2}^{U A}+\beta_{1} b p_{1}^{U A}+\beta_{2} p_{2}^{U A}
$$

The European definition is social welfare superior when the weighted price for the whole country is lower under this definition than under the American definition, i.e., when the inequality below holds:

$$
\alpha_{1} p_{1}^{U A}+\alpha_{2} p_{1}^{U A}+\beta_{1} b p_{1}^{U A}+\beta_{2} p_{1}^{U A}<\alpha_{1} p_{1}^{U A}+\alpha_{2} p_{2}^{U A}+\beta_{1} b p_{1}^{U A}+\beta_{2} p_{2}^{U A}
$$

or, rearranging, when:

$$
p_{1}^{U A}<p_{2}^{U A}
$$

which is true by the assumption of $\min \left\{p_{1}^{U A}, p_{2}^{U A}\right\}=p_{1}^{U A}$.

Under $S W_{2}$, it is trivial that the same result holds. We only need to remove $U$ market areas sizes from the weighted prices, and we see easily that the weighted prices under European definition is lower than under the American definition. 


\section{A.5 Proof Proposition 5}

Under $S W_{1}$, the regulator chooses $\theta$ to maximize:

$$
\begin{aligned}
\alpha_{1} \frac{\left(1-p_{1}^{U}(\theta)\right)^{2}}{2} & +\alpha_{2} \frac{\left(1-p_{2}^{U}(\theta)\right)^{2}}{2}+b \frac{\left(1-p^{R}(\theta)\right)^{2}}{2}+\alpha_{1} p_{1}^{U}(\theta)\left(1-p_{1}^{U}(\theta)\right)+ \\
& +\alpha_{2} p_{2}^{U}(\theta)\left(1-p_{2}^{U}(\theta)\right)+b p^{R}(\theta)\left(1-p^{R}(\theta)\right)
\end{aligned}
$$

where the first three terms are the consumers' surpluses from areas 1 and 2 of the $\mathrm{U}$ market and $\mathrm{R}$ market respectively, and the last two terms are the profits of firms, and where

$$
p_{1}^{U}(\theta)=\frac{\alpha_{1}\left(3 \alpha_{2}+2 b \beta_{2}(1-\theta)^{2}\right)+\alpha_{2} b \beta_{1} \theta(1+2 \theta)}{3\left(\alpha_{1}\left(3 \alpha_{2}+2 b \beta_{2}(1-\theta)^{2}\right)+2 \alpha_{2} b \beta_{1} \theta^{2}\right)},
$$

is the price in area 1 of the $\mathrm{U}$ market,

$$
p_{2}^{U}(\theta)=\frac{\alpha_{1}\left(\alpha_{2}+b \beta_{2}\left(3-5 \theta+2 \theta^{2}\right)\right)+2 \alpha_{2} b \beta_{1} \theta^{2}}{3\left(\alpha_{1}\left(3 \alpha_{2}+2 b \beta_{2}(1-\theta)^{2}\right)+2 \alpha_{2} b \beta_{1} \theta^{2}\right)},
$$

is the price in area 2 of the $\mathrm{R}$ market, and

$$
p^{R}(\theta)=\frac{\left.\alpha_{1}\left(\alpha_{2}+b \beta_{2}(1-\theta)^{2}\right)+\alpha_{2} b \beta_{1} \theta^{2}\right)}{3\left(\alpha_{1}\left(3 \alpha_{2}+2 b \beta_{2}(1-\theta)^{2}\right)+2 \alpha_{2} b \beta_{1} \theta^{2}\right)},
$$

is the price in the $\mathrm{R}$ market. Recall further that $\alpha_{1}+\alpha_{2}=1$, and $\beta_{1}+\beta_{2}=1$.

Differentiating the social welfare function, we have:

$$
\begin{aligned}
\frac{\partial S W_{1}(\theta)}{\partial \theta} & =-\alpha_{1}\left(1-p_{1}^{U}(\theta)\right) \frac{\partial p_{1}^{U}(\theta)}{\partial \theta}-\alpha_{2}\left(1-p_{2}^{U}(\theta)\right) \frac{\partial p_{2}^{U}(\theta)}{\partial \theta}-b\left(1-p^{R}(\theta)\right) \frac{\partial p R(\theta)}{\partial \theta}+ \\
+\alpha_{1}\left(1-p_{1}^{U}(\theta)\right) \frac{\partial p_{1}^{U}(\theta)}{\partial \theta}+\alpha_{2}\left(1-p_{2}^{U}(\theta)\right) \frac{\partial p_{2}^{U}(\theta)}{\partial \theta}+b\left(1-p^{R}(\theta)\right) \frac{\partial p^{R}(\theta)}{\partial \theta}- & \\
& -\alpha_{1} p_{1}^{U}(\theta) \frac{\partial p_{1}^{U}(\theta)}{\partial \theta}-\alpha_{2} p_{2}^{U}(\theta) \frac{\partial p_{2}^{U}(\theta)}{\partial \theta}-b p^{R}(\theta) \frac{\partial p^{R}(\theta)}{\partial \theta}=0
\end{aligned}
$$

Straightforward computations result in the first order conditions for maximum: 


$$
\frac{\partial W(\theta)}{\partial \theta}=-\alpha_{1} p_{1}^{U}(\theta) \frac{\partial p_{1}^{U}(\theta)}{\partial \theta}-\alpha_{2} p_{2}^{U}(\theta) \frac{\partial p_{2}^{U}(\theta)}{\partial \theta}-b p^{R}(\theta) \frac{\partial p^{R}(\theta)}{\partial \theta}=0
$$

From this first order condition, we cannot obtain a close form solution for $\theta$. Nevertheless, numerical resolution shows that for given $\alpha_{1}$ and $b$, the optimum for $\theta$ is unique. Further, we get

1. $\theta^{*}=1$ if $\beta_{1} \in\left[0, \underline{\beta_{1}}\right]$

2. $\theta^{*}=0$ if $\beta_{1} \in\left[\overline{\beta_{1}}\right]$

3. $\theta^{*} \in(0,1)$ if $\beta_{1} \in\left[\underline{\beta_{1}}, \overline{\beta_{1}}\right]$

as it is shown in figure 3 and 4 . From figure 3 , we can also see how $\beta_{1}$ and $\overline{\beta_{1}}$ are increasing function of $\alpha_{1}$. From figure 4 , we can see that $\beta_{1}$ is an increasing function of $b$ while $\overline{\beta_{1}}$ is a decreasing function of $b$. Finally, we have checked that these optima are indeed maxima.

\section{A.6 Proof Proposition 6}

Under $S W_{2}$ the regulator's objective function becomes:

$$
S W_{2}(\theta)=b \frac{\left(1-p^{R}(\theta)\right)^{2}}{2}
$$

Solving the first order condition for maximum we get:

$$
\frac{\partial S W_{2}(\theta)}{\partial \theta}=b\left(1-p^{R}(\theta)\right) \frac{\partial p^{R}(\theta)}{\partial(\theta)}=0 \Rightarrow \theta^{* *}=\frac{\alpha_{1}\left(1-\beta_{1}\right)}{\left(1-\alpha_{1}\right) \beta_{1}+\alpha_{1}\left(1-\beta_{1}\right.} .
$$

Since $S W_{2}(\theta)$ is a concave function as we can see in Figure 7, we can conclude that $\theta^{* *}$ is an optimal solution.

\section{A.7 Proof Proposition 7}

We start from the case when in equilibrium $p^{R}=\min \left\{p_{1}^{U A}, p_{2}^{U A}\right\}$ and we suppose that $\min \left\{p_{1}^{U A}, p_{2}^{U A}\right\}=p_{1}^{U A}$. Therefore areas 1 and 2 of the $\mathrm{R}$ market enjoy a price $p_{1}^{U A}$, as well as area 1 of the $\mathrm{U}$ market. Area 2 of the $\mathrm{R}$ 
market enjoys the symmetric Cournot price which is lower than $p_{1}^{U A}$. We can construct a weighted price for the whole country under this definition:

$$
\alpha_{1} p_{1}^{U A}+\alpha_{2} p^{C}+b p_{1}^{U A}
$$

where $p^{C}$ is the symmetric Cournot price. On the other hand, the European definition applies $p_{1}^{U A}$ to the whole country. Thus, the weighted price for the whole country is:

$$
\alpha_{1} p_{1}^{U A}+\alpha_{2} p_{1}^{U A}+b p_{1}^{U A}
$$

The new definition is superior in terms of social welfare if it gives a lower weighted price than the European definition. This happens if

$$
\alpha_{1} p_{1}^{U A}+\alpha_{2} p^{C}+b p_{1}^{U A}<\alpha_{1} p_{1}^{U A}+\alpha_{2} p_{1}^{U A}+b p_{1}^{U A}
$$

or equivalently, if $p^{C}<p_{1}^{U A}$, what is true. Therefore, the new definition is superior to the European definition, whenever we apply $\min \left\{p_{1}^{U A}, p_{2}^{U A}\right\}$. If we take into account that we only apply either $\max \left\{p_{1}^{U A}, p_{2}^{U A}\right\}$ or $\theta^{*} \in(0,1)$ when they are social welfare superior to $\min \left\{p_{1}^{U A}, p_{2}^{U A}\right\}$, we can conclude that this definition is always social welfare superior to the European definition, and by extension to the American as we have shown previously.

\section{A.8 Proof Proposition 8}

The firms that operate in both areas maximize:

$$
\begin{gathered}
\Pi_{S j}=\left(1-\frac{\left(q_{S j}+q_{N j}\right)}{\alpha_{j}}\right) q_{S j}+ \\
\left(1-\left(\frac{\left(q_{S k}+q_{N k}\right)}{\alpha_{k}}\right)-c\right)\left(\frac{\beta_{j} b\left(q_{S k}+q_{N k}\right)}{\alpha_{k}}\right)-F_{j}^{U}-F_{j}^{R}+s_{j} \\
j=1,2, k \neq j .
\end{gathered}
$$

If we take the derivative of the profit function with respect to $q_{1 j}$, we obtain the first order conditions: 


$$
\frac{\partial \Pi_{S j}}{\partial q_{s j}}=\left(1-\left(\frac{2 q_{S j}+q_{N j}}{\alpha_{j}}\right)\right)=0, j=1,2
$$

The firms that only operate in the areas of the $\mathrm{U}$ market maximize:

$$
\Pi_{N j}=\left(1-\frac{\left(q_{S j}+q_{N j}\right)}{\alpha_{j}}\right) q_{N j}-F_{j}^{U}, j=1,2
$$

If we take the derivative of the profit function with respect to $q_{N j}$, we obtain the first order conditions:

$$
\frac{\partial \prod_{N j}}{\partial q_{N j}}=\left(1-\left(\frac{q_{S j}+2 q_{N j}}{\alpha_{j}}\right)\right)=0, j=1,2
$$

These first order conditions yield the following equilibrium quantities:

$$
q_{S j}^{*}=\frac{\alpha_{j}}{3}, q_{N j}^{*}=\frac{\alpha_{j}}{3}, j=1,2
$$

If we substitute the equilibrium quantities in the demand function, we obtain the equilibrium price for the areas of the $U$ market which is the symmetric Cournot price:

$$
p_{j}^{U *}=\left(1-\frac{q_{S j}^{*}+q_{N j}^{*}}{\alpha_{j}}\right)=\frac{1}{3}, j=1,2
$$

As we have seen previously, the prices in the zones are the same for both areas, therefore, the symmetric Cournot price is also set in the areas of the $\mathrm{R}$ market. 
Figure 1

Zone $1=\operatorname{area} \mathrm{R} 1+\operatorname{area} \mathrm{U1}$

Zone $\mathbf{2}=$ area $\mathbf{R} 2+$ area $\mathrm{U} 2$

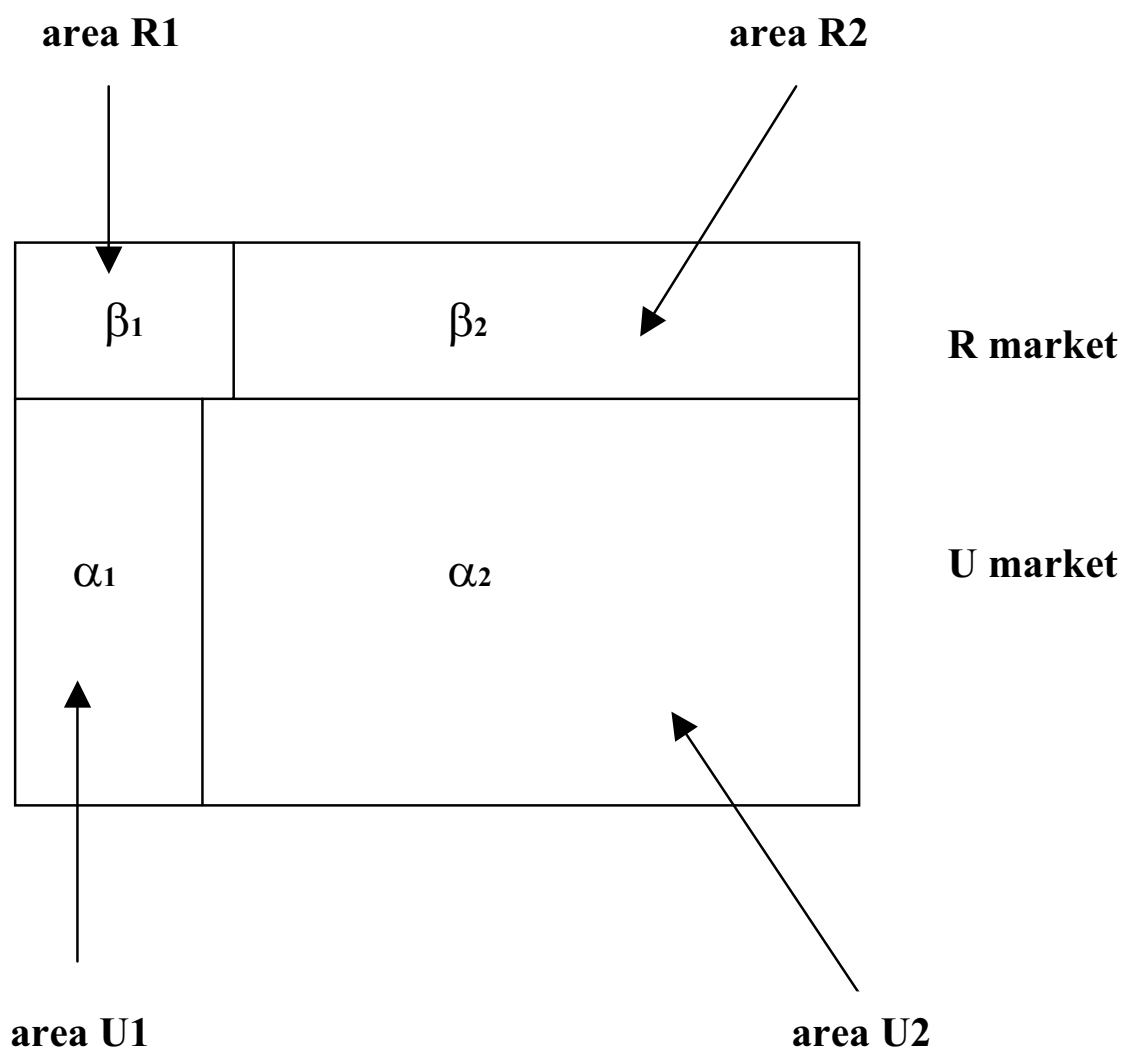




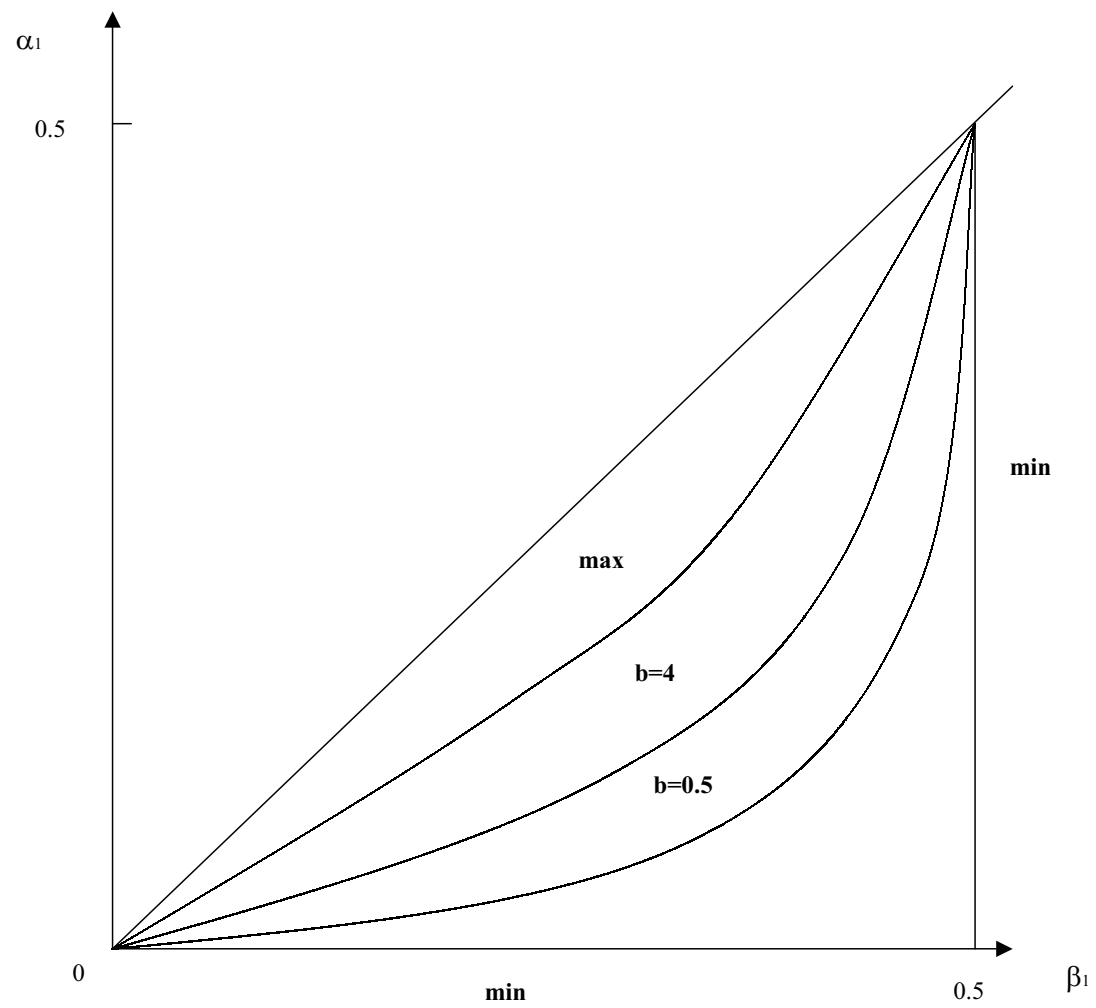

Figure 2: The regulator optimal choice between $\max \left\{p_{1}^{U A}, p_{2}^{U A}\right\}$ and $\min \left\{p_{1}^{U A}, p_{2}^{U A}\right\}$ 


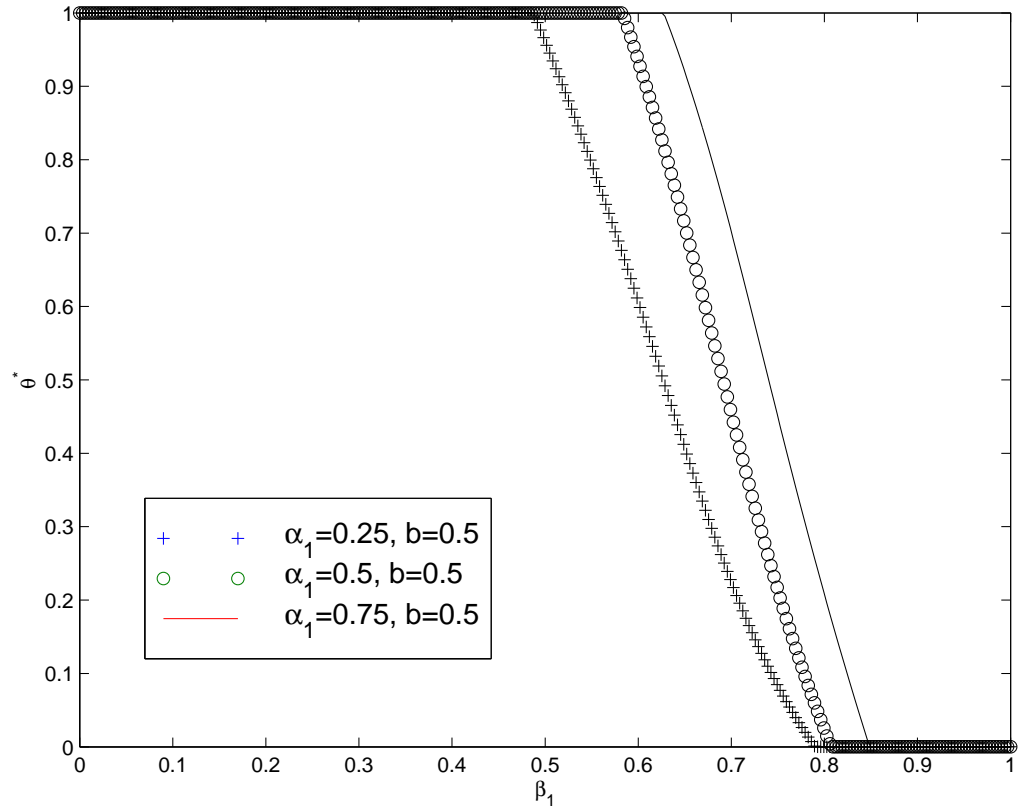

Figure 3: Equilibrium path for $\theta^{*}$ under different values of $\alpha_{1}$.

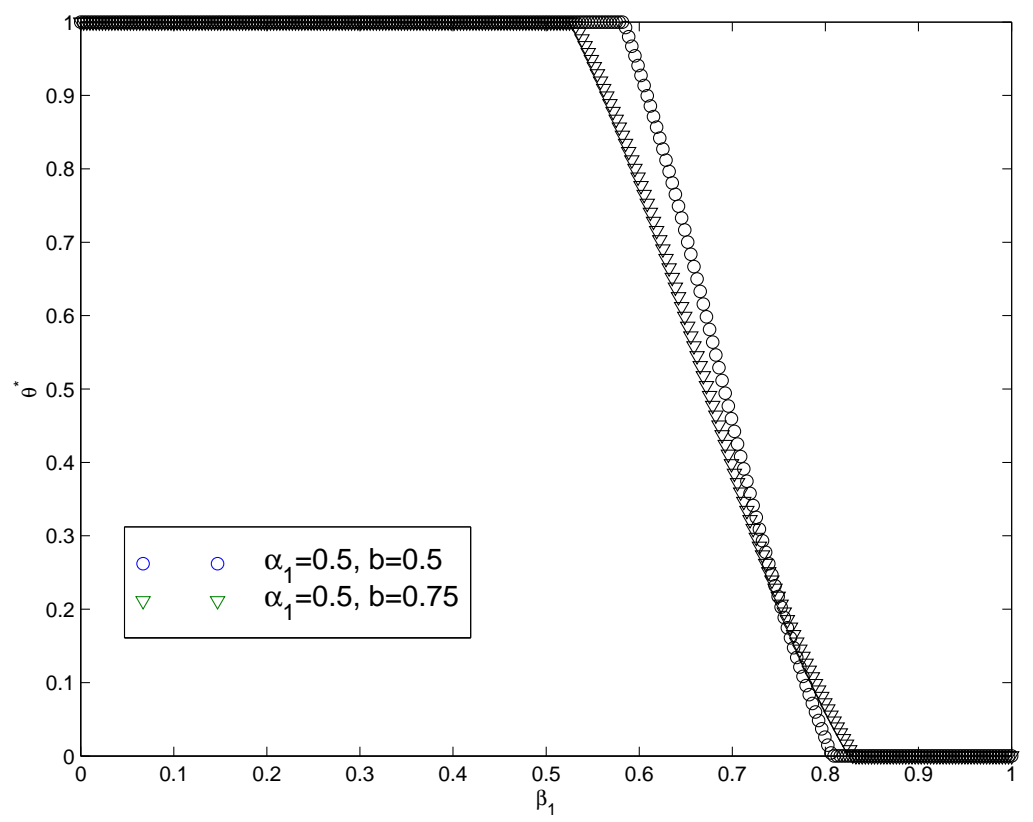

Figure 4: Equilibrium path for $\theta^{*}$ under different values of $b$. 


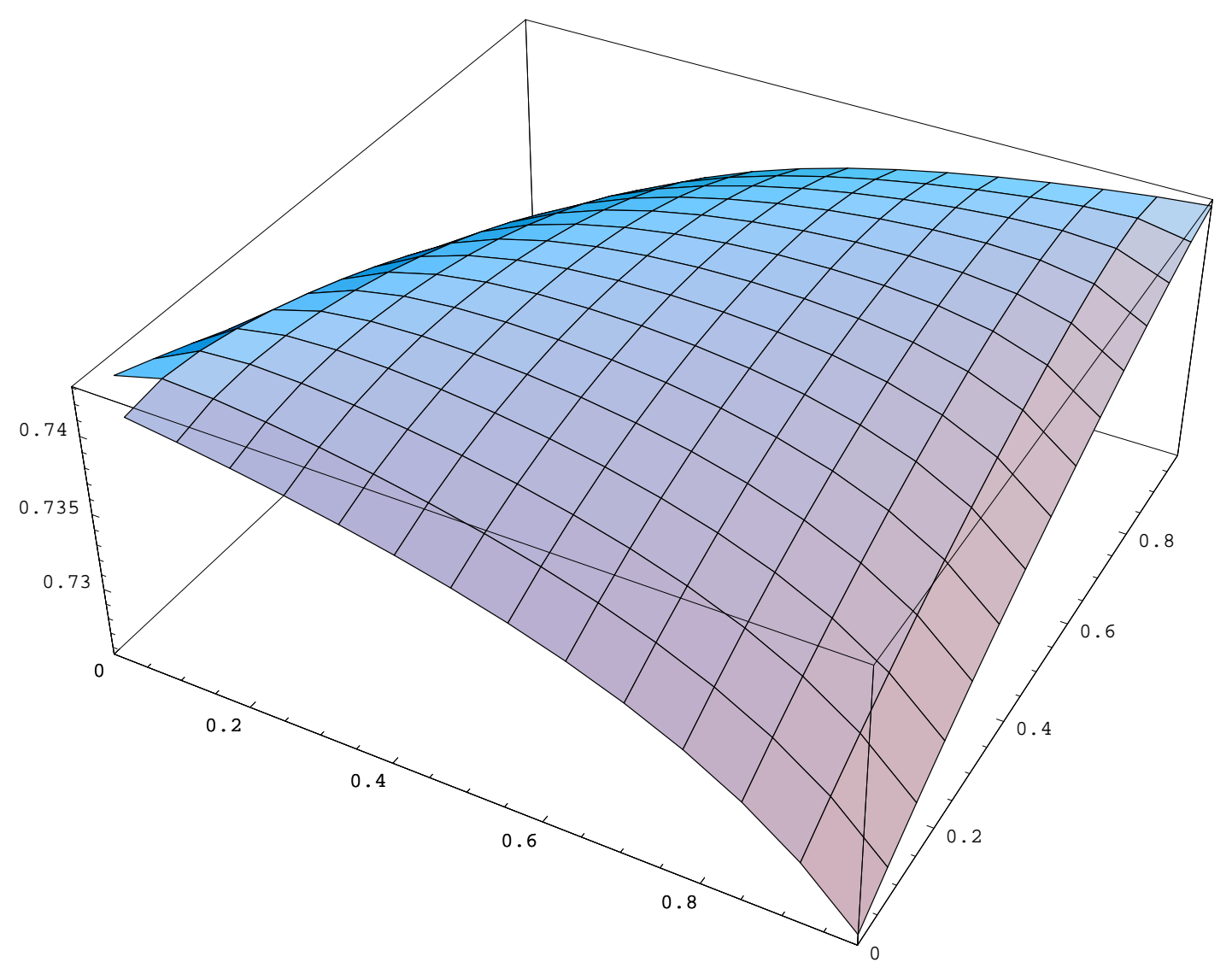

Figure 5: Social Welfare Function $S W_{1}$. 


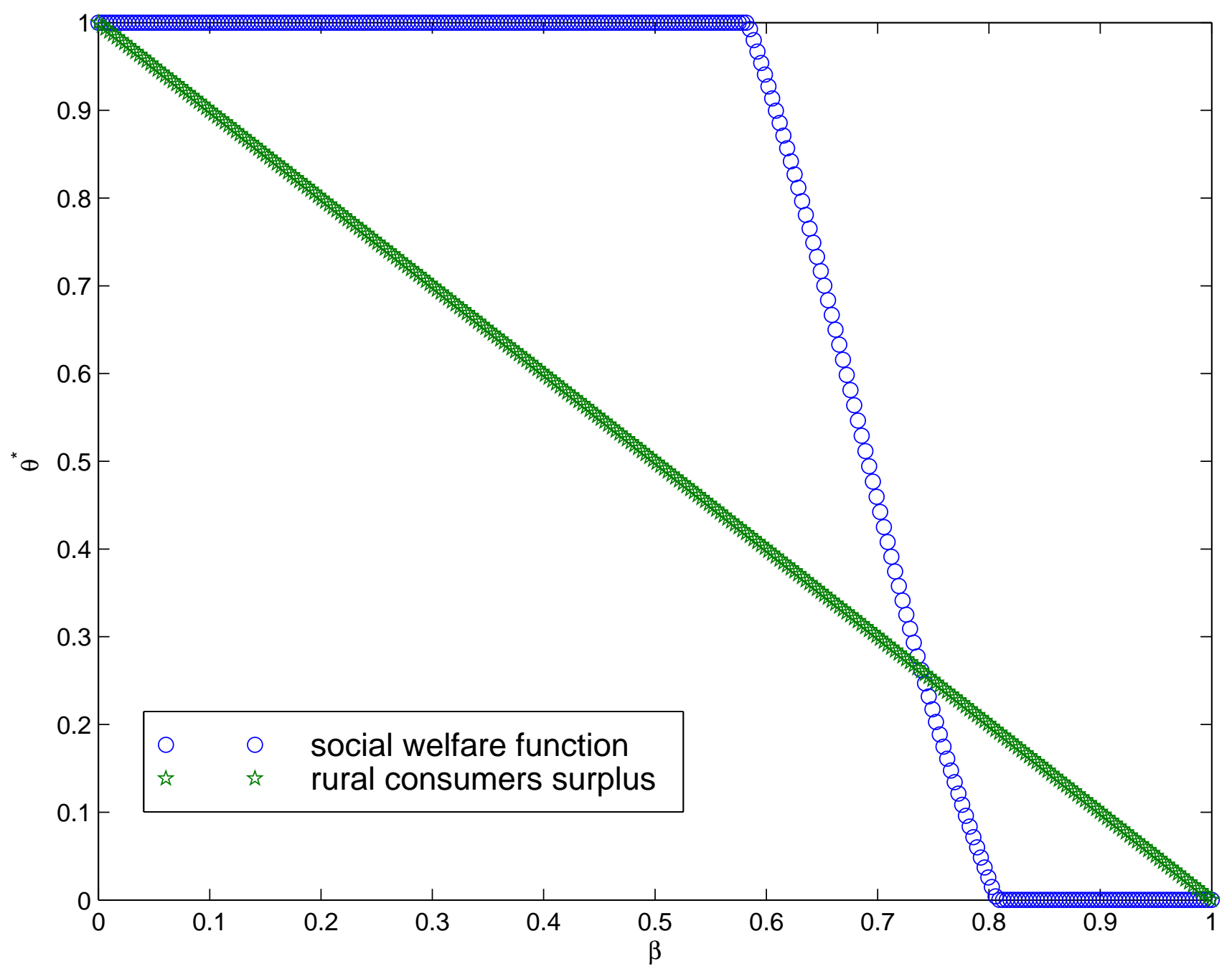

Figure 6: Equilibrium path for $\theta^{*}$ and $\theta^{* *}$ under both definitions of Social Welfare. 


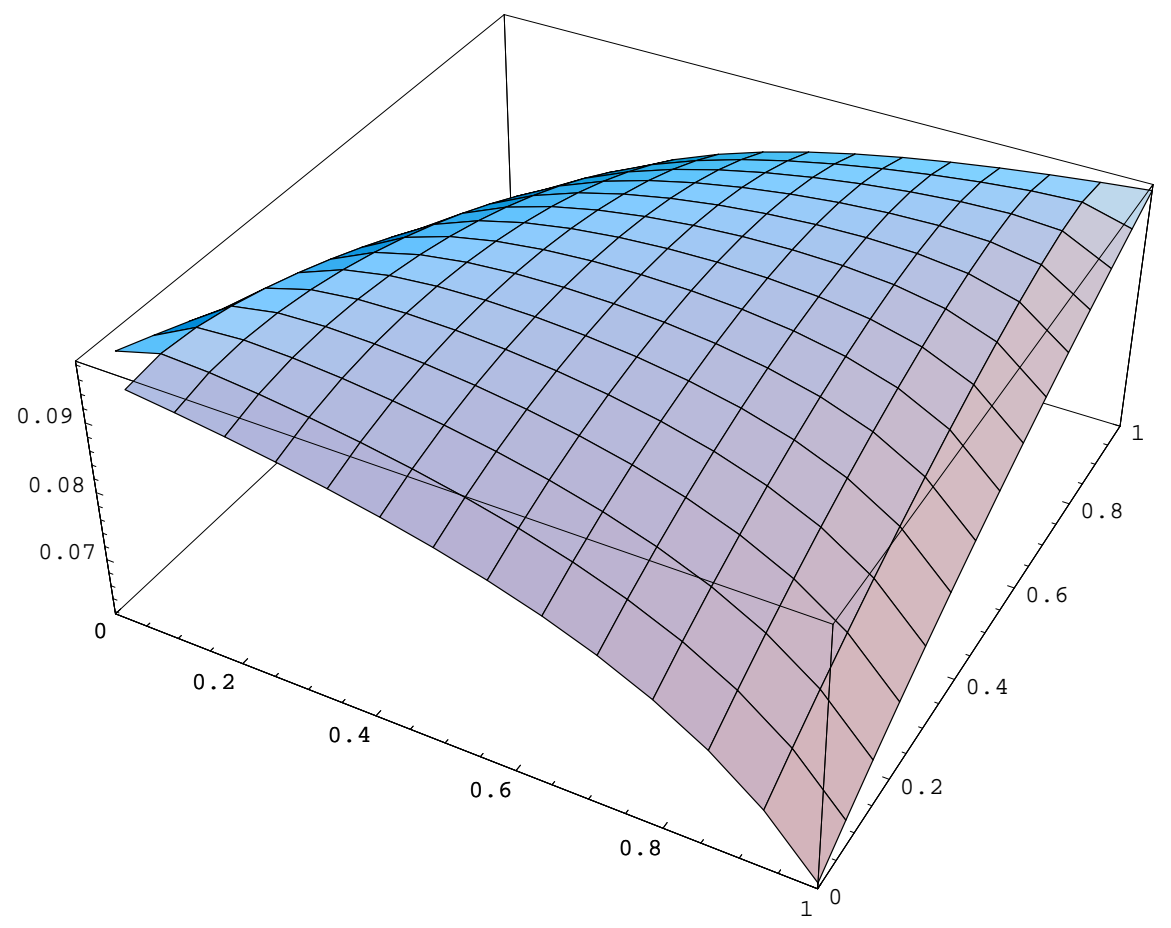

Figure 7: Social Welfare Function $S W_{2}$. 